\title{
Large-Scale Analysis of Cell Death Phenotypic Heterogeneity
}

Zintis Inde ${ }^{1}$, Giovanni C. Forcina ${ }^{1}$, Kyle Denton ${ }^{1}$, Scott J. Dixon ${ }^{1 *}$

${ }^{1}$ Department of Biology, Stanford University, Stanford, CA 94305, USA

94305, USA

*Lead contact: sjdixon@stanford.edu 


\section{SUMMARY}

Individual cancer cells within a population can exhibit substantial phenotypic heterogeneity such that exposure to a lethal agent will kill only a fraction of cells at a given time. Whether common molecular mechanisms govern this fractional killing in response to different lethal stimuli is poorly understood. In part, this is because it is difficult to compare fractional killing between conditions using existing approaches. Here, we show that fractional killing can be quantified and compared for hundreds of populations in parallel using high-throughput time-lapse imaging. We find that fractional killing is highly variable between lethal agents and between cell lines. At the molecular level, we find that the antiapoptotic protein MCL1 is an important determinant of fractional killing in response to mitogen activated protein kinase (MAPK) pathway inhibitors but not other lethal stimuli. These studies lay the foundation for the large-scale, quantitative analysis of cell death phenotypic heterogeneity. 


\section{INTRODUCTION}

Individual cells within a population often behave differently even when exposed to the same environment. This heterogeneity is apparent in both prokaryotic and eukaryotic cells, and affects a wide range of phenotypes including morphology, chemotaxis, and the response to lethal drug treatment (Bigger, 1944; Santos et al., 2019; Sharma et al., 2010; Spudich and Koshland, 1976; Wu et al., 2020). Such differences can arise in a non-genetic manner due to random fluctuations within molecular networks impacting gene or protein expression, epigenetic states, metabolism and other factors (Niepel et al., 2009). It is of great interest to understand the nature of this heterogeneity at the cellular and molecular levels and how it contributes to specific biological outcomes.

Phenotypic heterogeneity is apparent in the response of cancer cells to lethal drugs. At a simple level, lethal drugs can generally be titrated such that only a fraction of the total number of cells within a population are killed at a given dose and time (Figure 1A) (Fallahi-Sichani et al., 2013). This heterogeneity may be related to fractional killing (FK), a clinical phenomenon where a constant fraction of tumor cells are killed in response to each cycle of drug administration rather than a constant number (Berenbaum, 1972; Skipper, 1965). FK provides a useful conceptual paradigm within which to examine cell death phenotypic heterogeneity in vitro. Here, FK has been linked to differences between cells in the expression or activity of several pro-apoptotic and signaling molecules, including caspases, p53, and the c-Jun N-terminal kinase (JNK) pathway (Miura et al., 2018; Paek et al., 2016; Roux et al., 2015; Spencer et al., 2009). How FK varies between lethal 
conditions, and whether FK in response to different lethal stimuli is governed by a core molecular mechanism or is stimuli-specific, is largely unclear. In part, this is due to the low-throughput nature of existing methods to assess FK.

Here, we examine phenotypic heterogeneity within the framework of druginduced cancer cell FK. In particular, we sought to determine whether the nature of FK varies between lethal conditions and is regulated by common or contextspecific mechanisms. We find that it is possible to systematically quantify FK under many conditions in parallel using high-throughput population-level time-lapse imaging and associated mathematical modelling. We identify the anti-apoptotic protein MCL1 specifically as one important regulator of FK in response to inhibitors of the mitogen activated protein kinase (MAPK) cascade, but not other lethal stimuli. Our results demonstrate that it is possible to analyze FK on a large-scale basis and suggest that this phenomenon is governed by diverse molecular mechanisms.

\section{RESULTS}

\section{Traditional cell viability assays do not report effectively on fractional killing}

We sought to determine whether shared molecular mechanisms regulate FK in response to different lethal stimuli and across genetic backgrounds. We also reasoned that it would be important to disentangle the potential effect of drug dose on FK (e.g. intermediate drug doses may yield FK simply due to variable target engagement between cells in the population (Mateus et al., 2017)). Thus, for this analysis, the ideal approach would enable us to assess FK accurately for many 
different drug treatment conditions in parallel. At the beginning of our studies, the best approach was unclear. Population cell death is typically inferred in large-scale studies using metabolism-based cell viability assays (Kepp et al., 2011). These assays are simple, affordable, and highly accessible. To test if these methods would be suitable, we examined cell viability in two genetically distinct cancer cell lines, U-2 $\mathrm{OS}^{\mathrm{N}}$ osteosarcoma and $\mathrm{T}^{\mathrm{N}} \mathrm{G}^{\mathrm{N}}$ glioblastoma, using two common metabolism-based assays, CellTiter-Glo (CTG) and PrestoBlue (PB). As test lethal perturbations, both cell lines were treated with a ten-point, two-fold doseresponse series of three mechanistically-distinct lethal compounds (etoposide, bortezomib and vinblastine) for 72 h. U-2 $\mathrm{OS}^{\mathrm{N}}$ and $\mathrm{T}^{\mathrm{N}} \mathrm{G} \mathrm{G}^{\mathrm{N}}$ cells express the live cell marker nuclear-localized mKate2 (denoted by the superscript 'N', (Forcina et al., 2017)). Crucially, this enabled us to benchmark CTG and PB measurements against live cell counts from these same populations and examine how CTG and PB measures compared to actual cell counts.

As expected, CTG and PB measurements and live cell counts declined with increasing concentrations of all three compounds in both cell lines (Figure S1A-D, and not shown). However, changes in CTG and PB measurements frequently did not correlate linearly with live cell counts. For example, in U-2 OS ${ }^{\mathrm{N}}$ cells, treatment with $400 \mathrm{nM}$ or $1.6 \mu \mathrm{M}$ etoposide resulted in CTG and PB measurements that were within error of one another, despite differing by $35 \%$ in live cell counts (Figure S1A,C). Similar discrepancies were likewise observed in $\mathrm{T} 8 \mathrm{G}^{\mathrm{N}}$ cells treated with bortezomib or vinblastine (Figure S1B,D). We also observed that CTG and PB measurements were not constant on a per cell basis, being substantially increased 
at higher compound concentrations, possibly due to compound effects on mitochondrial function (Chan et al., 2013) (Figure S1E,F). Per cell CTG and PB values also varied considerably between $U-2$ OS $^{N}$ and $T 98 G^{N}$ cell lines (Figure S1C,E). Collectively, these results suggested that metabolism-based measures of cell viability would not be suitable for a comparative analysis of heterogeneous cell death between populations.

\section{Analyzing fractional killing using high-throughput time-lapse microscopy}

Our results prompted us to consider alternative methods for evaluating FK. In particular, we assessed the utility of high-throughput time-lapse imaging. This approach is less accessible than traditional cell viability assays, but can enable both live (mKate2 ${ }^{+}$) and dead (SYTOX Green-positive) cells to be counted in many populations in parallel over time, as we have recently demonstrated (Figure 1B) (Forcina et al., 2017). Accordingly, we hypothesized that high-throughput timelapse imaging of live and/or dead cells would enable effective quantification of FK across conditions. To begin testing this hypothesis, we examined populations of U-2 $\mathrm{OS}^{\mathrm{N}}$ and $\mathrm{T}^{\mathrm{N}} \mathrm{G}^{\mathrm{N}}$ cells treated with a panel of ten different lethal compounds, each tested in 10-point, two-fold dose-response series. For all 200 conditions, live and dead cells were counted every $2 \mathrm{~h}$ for a total of $120 \mathrm{~h}$ and the resultant dataset visualized using heatmaps (Figure 1C, S1G).

All compounds reduced live cell counts and increased dead cell counts at one or more tested concentrations in both cell lines (Figure 1D, S1G). At high drug concentrations, we typically observed a decrease in live cells by the end of the 
observation period that equaled the increase in dead cells. However, at intermediate lethal doses, live or dead cell counts alone did not accurately reflect total population cell death over time. For example, in U-2 OSN cells treated with an intermediate dose of camptothecin $(0.04 \mu \mathrm{M}), \mathrm{MG} 132(0.63 \mu \mathrm{M})$ or erastin $(1.3$ $\mu \mathrm{M}), \mathrm{mKate}^{+}$live cell counts at $120 \mathrm{~h}$ were similar to those observed at the start of the experiment, despite extensive cell death within the population as indicated by increased $\mathrm{SG}^{+}$dead cell counts (Figure 1D). Similar observations were made in $\mathrm{T} 8 \mathrm{G}^{\mathrm{N}}$ cells treated with intermediate concentrations of MG132 or thapsigargin (Figure $\mathrm{S} 1 \mathrm{H}$ ). This effect was best explained by the fact that most lethal treatments did not start killing cells immediately upon addition. Rather, populations typically increased in cell number for several hours prior to the onset of cell death, expanding the initial size of the population subsequently available to die (Figure $1 \mathrm{C}, \mathrm{D}, \mathrm{S} 1 \mathrm{G}, \mathrm{H})$. We therefore concluded that to assess FK it was essential to track both live and dead cells, as done in low-throughput experimental designs (Miura et al., 2018; Paek et al., 2016; Spencer et al., 2009).

Counts of live and dead cells alone do not provide a uniform metric for FK that is easy to compare across conditions. We previously described how counts of live and dead cells over time could be integrated into a single metric, the lethal fraction, which summarizes overall population cell death (Forcina et al., 2017) (Figure 1B). We hypothesized that lethal fraction scores would be a useful metric for FK within any given population. In support of this hypothesis, lethal fraction scores correctly accounted for the partial population cell death observed at intermediate compound doses noted above (Figure 1C,D, S1G,H). Interestingly, 
examination of lethal fraction scores over time made clear that FK is inherently a time dependent phenomenon. For example, in $\mathrm{U}-2 \mathrm{OS}^{\mathrm{N}}$ cells treated with $10 \mu \mathrm{M}$ camptothecin, the first $10 \%$ of cells died by $24 \mathrm{~h}$ while the last $10 \%$ of cells did not die until after $80 \mathrm{~h}$ of treatment (Figure 1D). Similar variability in the span of time between the first and last cell deaths within the population were apparent for all lethal compounds examined, and in some cases (e.g. paclitaxel) this varied considerably between cell lines (Figure 1E-H). We conclude that high-throughput time-lapse imaging and lethal fraction scoring comprise a useful approach to assess FK on a common scale that can be compared across conditions.

\section{Fractional killing kinetics vary between lethal conditions}

Lethal fraction scores provided a useful means to visualize different patterns of FK over time in response to different lethal treatment. However, further abstraction of these data was necessary to simplify the process of comparing FK between conditions. Recently we showed that lethal fraction scores over time can be fitted with a lag exponential death (LED) model that allows for the extraction of two key parameter values describing cell death within the population: $D_{0}$ and $D_{R}$ (Figure 2A) (Forcina et al., 2017). Previously we focused on Do, which reflects the time when the first cells in a population begin to die. By contrast, $D_{R}$ captures the maximal rate of cell death within the population (i.e. the maximum slope of the lethal fraction curve) and is represented here as the rate of change in lethal fraction (expressed as a percentage of dead cells) over time $\left(\% \mathrm{~h}^{-1}\right)$. $\mathrm{D}_{\mathrm{R}}$ reflects the degree of heterogeneity in the initiation of cell death between cells within the population: 
high $D_{R}$ values are observed when cells within the population die all around the same time, while low $D_{R}$ values indicate that cells within the population are dying at very different times (Figure 2B). We therefore hypothesized that the $D_{R}$ parameter value would provide a powerful means to summarize FK within a population and compare these values across conditions.

To test this hypothesis, we examined how $D_{R}$ varied for a subset of lethal conditions examined in $\mathrm{U}-2 \mathrm{OS}^{\mathrm{N}}$ and $\mathrm{T}^{\mathrm{N}} \mathrm{GG}^{\mathrm{N}}$ cells. In principle, a condition where cell death is initiated at the same time in all cells within the population could have $D_{R}$ equal to $\sim 100 \% \mathrm{~h}^{-1}$. Strikingly, while $D_{R}$ varied between lethal compounds, it rarely exceeded $6 \% \mathrm{~h}^{-1}$ (Figure $2 \mathrm{C}$ ). In fact, in many cases $\mathrm{D}_{\mathrm{R}}$ was below $3 \% \mathrm{~h}^{-1}$, even at the highest tested compound concentrations. These $D_{R}$ values suggest that cells within the population execute cell death at very different times, a phenotype we confirmed by visual inspection (Figure 2D, S2A,B). $D_{R}$ captures this cellular heterogeneity and illustrates the degree to which FK within a population is fundamentally time dependent. Notably, this time dependence could not easily have been captured by endpoint measurements of CellTiter-Glo and PrestoBlue metrics.

To further test our hypothesis, we examined how FK varied between 140 mechanistically-diverse lethal compounds tested in U-2 OS osteosarcoma cells at a single dose of $5 \mu \mathrm{M}$ (Figure 2E) (Forcina et al., 2017). 139 of 140 compounds yielded lethal fraction scores over time (120 h of observation) where it was possible to determine $D_{R}$ values. Across all compounds, median $D_{R}$ was $2.4 \% h^{-1}(1.6$ $4.6 \% \mathrm{~h}^{-1}$ interquartile range) (Figure $2 \mathrm{~F}$ ), consistent with analysis of a more limited 
set of lethal compounds above. Most compounds in this set have a specific molecular target, allowing us to ask whether FK varied by compound target. Consistent with our previous analysis (Forcina et al., 2017), $D_{R}$ varied by compound class, with proteasome inhibitors and HDAC inhibitors triggering relatively fast $\mathrm{FK}$ (median $\mathrm{D}_{\mathrm{R}}>5 \% \mathrm{~h}^{-1}$ ), and inhibitors of cyclin-dependent kinases (CDK), microtubule function, and especially mitogen-activated protein kinase kinase 1 and 2 (MEK1/2) causing relatively 'slow' FK (median $D_{R}<2 \% h^{-1}$ ) (Figure $2 \mathrm{G}, \mathrm{H})$. Thus, the rate of FK over time can vary substantially between lethal compound classes.

\section{MEK1/2 inhibitors trigger slow FK not involving many known mechanisms}

MEK1/2 inhibitors (MEKis) block the function of the important RAS/MAPK signal transduction pathway (Figure 3A). The slow kinetics of MEKi-induced FK were intriguing. We sought to identify molecular mechanisms that modulate this process and test whether these mechanisms were generalizable to other lethal compounds. MEKis are being investigated for use in the treatment of various cancers, including lung (Kim and Giaccone, 2018; Robert et al., 2019). We therefore pursued our follow-on studies using non-small cell lung carcinoma (NSCLC) models. Crucially, the structurally-distinct MEKis pimasertib (Pim) and trametinib (Tram) triggered slow $\mathrm{FK}\left(\mathrm{D}_{\mathrm{R}}<3 \% \mathrm{~h}^{-1}\right)$ across a range of lethal concentrations in three different KRAS-mutant NSCLC cell lines, A549, Calu-6 and H2291, consistent with a broadly generalizable FK phenotype (Figure 3B,C, S3A). 
A trivial explanation for FK is variable inhibition of the drug target. However, phosphorylation of the MEK1/2 substrates ERK1/2 was fully inhibited by Pim in as little as $2 \mathrm{~h}$, long before the initiation of cell death, with a lethal concentration (i.e. $5 \mu \mathrm{M}$ ) resulting in sustained inhibition of ERK1/2 phosphorylation over $48 \mathrm{~h}$ (Figure 3D,E). Using the single-cell ERK kinase translocation reporter (KTR) (Regot et al., 2014), we found that lethal MEKi treatment resulted in greater reporter nuclear translocation before the onset of cell death than non-lethal MEKi treatment or lethal control (i.e. bortezomib) treatment (Figure 3F). Thus, differential inhibition of ERK1/2 phosphorylation did not explain slow FK in response to MEKis.

We next sought to identify proteins or processes downstream of MEK1/2 that could mediate slow FK. Similar to MEKis, direct inhibition of ERK1/2 using the small molecule ERK1/2 inhibitor (ERKi) SCH772984 resulted in slow FK in both A549 ${ }^{N}$ and Calu-6 ${ }^{N}$ cells (Figure 3G, S3B). We confirmed that SCH772984 effectively reduced the expression of DUSP4, a target of the MAPK pathway, at both $2 \mathrm{~h}$ and $48 \mathrm{~h}$ (Cagnol and Rivard, 2013) (Figure 3H,I). The similar MEK1/2i and ERKi phenotypes argued against the existence of an inherently drug resistant (i.e. mutant) sub-population. Indeed, Pim triggered FK with similar kinetics in both a drug-naïve cells and cells that survived an initial round of MEKi treatment (Figure 3J). Rather, we hypothesized that slow FK was due to non-genetic molecular heterogeneity downstream or in parallel to ERK1/2. Several known candidate mechanisms of FK (Inde and Dixon, 2018), including p53 stabilization, cell cycle phase, glycolytic or oxidative metabolism, and reactive oxygen species (ROS) accumulation, did not contribute to MEKi-induced FK (Figure S3C-J). Thus, the 
molecular heterogeneity contributing to FK in response to MAPK pathway inhibition appeared to reside elsewhere in the cellular network.

\section{Variable MCL1 expression contributes to slow FK}

How inhibition of the MAPK pathway induced FK with such slow kinetics remained unclear. Given our ability to quantify FK for multiple independent conditions in parallel, we conducted a series of mechanistic investigations to explore this question. Testing the role of protein synthesis, we found that MEKiinduced cell death was potently suppressed by co-treatment with cycloheximide, suggesting that the translation of certain gene products was necessary for cell death (Figure S4A). Using RNA sequencing (RNA-Seq) we found a set of 555 genes significantly upregulated by lethal (i.e. $5 \mu \mathrm{M}$ ) Pim treatment in both $\mathrm{A} 549^{\mathrm{N}}$ and Calu- $6^{N}$ cells that was enriched for regulators of apoptosis (Figure 4A,B). Indeed, cell death induced by MEKis or the positive control bortezomib was suppressed by co-treatment with the pan-caspase inhibitor Q-VD-OPh (Figure S4B). Inhibition of the MAPK pathway can induce apoptosis, and variable expression of apoptotic proteins is linked to FK in other contexts (Boucher et al., 2000; Hata et al., 2014; Roux et al., 2015; Spencer et al., 2009; Zhao and Adjei, 2014). Accordingly, we focused on how the apoptosis pathway impacted slow FK in response to MEKis.

Based on literature precedent, we first examined the roles of the proapoptotic BH3-only protein BIM and the antiapoptotic protein BCL-xL (Cragg et al., 2008; Hata et al., 2014; Luciano et al., 2003; Meng et al., 2010). As expected, BIM 
levels increased, and BCL-xL levels decreased, following MEKi treatment in both A549 ${ }^{\mathrm{N}}$ and Calu-6 ${ }^{\mathrm{N}}$ cells (Figure S4C). We hypothesized that if slow FK was due to heterogenous expression of either protein, BIM overexpression or BCL-XL inhibition alone should promote the synchronization of cell death within the population. Specifically, such an effect would be apparent in higher $D_{R}$ values in response to MEKi treatment. Doxycycline (Dox)-inducible overexpression of wildtype BIM, but not inactive BIM ${ }^{\mathrm{G} 156 \mathrm{E}}$ (Marani et al., 2002), did shorten the time to cell death onset (i.e. $D_{0}$ ) but did not alter $D_{R}$ in response to MEKis, across a range of tested Dox doses (Figure S4D-H). Likewise, co-treatment of A549 ${ }^{\mathrm{N}}$ cells with the BCL-xL/BCL-2 inhibitor ABT-737 or the BCL-xL-selective inhibitor A-1155463 shortened $D_{0}$ without increasing $D_{R}$ (Figure 4C-E). Thus, BIM and BCL-xL helped set the threshold for MEKi-induced cell death but were not primary regulators of the heterogeneous nature of this process between cells.

In addition to $B C L-x L$, the antiapoptotic protein $M C L 1$ can also regulate apoptosis in response to inhibition of the MAPK pathway (Montero et al., 2019; Nangia et al., 2018; Pétigny-Lechartier et al., 2017; Sale et al., 2019). Interestingly, cotreatment with the selective MCL1 inhibitor S63845 shortened Do but also more than doubled MEKi-induced $D_{R}$, from less than $2 \% h^{-1}$ to over $4 \% h^{-1}$ in $A 549^{N}$ cells (Figure 4F,G). This effect was specific to MEKis, as MCL1 inhibition did not alter $D_{R}$ in response to the proteasome inhibitor bortezomib (Figure 4F,G). Similar but quantitatively weaker effects on $D_{R}$ were observed in S63845-treated Calu- ${ }^{N}$ cells in response to MEKi treatment (Figure S4I,J). Consistent with the small molecule inhibitor data, polyclonal CRISPR/Cas9-mediated MCL1 disruption enhanced 
MEKi-induced FK (Figure S4K,L, and see below). Thus, MCL1 was an important negative regulator of MEKi-induced slow FK.

Given the above results, we examined how MCL1 expression varied between individual cells, as determined using protein immunofluorescence, in response to MEKi treatment. As a comparison, we also examined the expression of BCL-xL. Consistent with our bulk analysis, Pim treatment $(5 \mu \mathrm{M}, 48 \mathrm{~h})$ reduced single cell BCL-xL protein levels (Mann Whitney test, $P<0.0001$ ) (Figure $4 \mathrm{H}$ ). BCL-xL expression was also more homogeneous between cells following Pim treatment, as inferred from the coefficient of variation in protein expression (Figure 4H). By contrast, the levels of MCL1 increased following Pim treatment, and variation in protein expression between cells remained high (Figure $4 \mathrm{H}$ ). Indeed, when examined in response to MEKi treatment over time, MCL1 levels became increasingly heterogeneous, as assessed either by coefficients of variation or the range of absolute MCL1 expression between remaining live cells (Figure 4I). Higher expression of MCL1 in an individual cell could inhibit cell death by allowing for greater sequestration of pro-apoptotic BH3-only proteins. Consistent with this model, enforced MCL1 overexpression significantly reduced the population death rate (i.e. $D_{R}$ ) in response to MEKis (Figure $4 \mathrm{~J}-\mathrm{L}$ ). We conclude that heterogeneous MCL1 expression between cells is an important contributor to $\mathrm{FK}$ in response to MAPK pathway inhibitors.

\section{The regulation of FK is lethal stimulus-specific}


Whether the molecular mechanisms governing FK vary between lethal stimuli, or are shared, is poorly understood. Our evidence suggested that the mechanisms governing FK in response to MEKis were unlikely to be shared with other lethal molecules. Further support for this model was obtained from the analysis of a series of fifteen (sub-) clonal cell lines isolated from our starting population of $A 549^{N}$ cells, each exposed to Pim $(5 \mu \mathrm{M})$, Tram $(0.5 \mu \mathrm{M})$, bortezomib (Btz, $50 \mathrm{nM})$ or erastin2 (Era2, $2 \mu \mathrm{M})$, and examined in parallel using time-lapse imaging (Figure 5A). Substantial variability was observed been these clonal populations in MEKi-induced FK, while more consistent responses were observed in response to both Btz and Era2 (Figure 5B). This directly demonstrates that the molecular mechanisms governing FK in response to MEKis are distinct from those contributing to FK in response to other lethal stimuli. This experiment also further highlighted the utility of highly parallelized analysis of FK for comparative studies.

These clonal cell lines also provided an opportunity to study how differences in MEKi-induced FK related to the expression of MCL1. Based on our existing data (Figure 4H-L), we hypothesized that high levels of MCL1 expression would correlate with relative resistance to MEKi-induced FK. To test this hypothesis, we picked clones that exhibited relatively low (\#6 and \#15) or high (\#10 and \#16) sensitivity to MEKi-induced FK and examined protein expression. Both low and high sensitivity clones exhibited similar basal phosphorylated ERK1/2 and BCL-XL expression, and similar loss of both species following MEKi treatment (Figure 5C). By contrast, low sensitivity clones accumulated substantially higher levels of MCL1 and BIM following MEKi treatment compared to high sensitivity clones (Figure 5C). 
Thus, high levels of MCL1 accumulation correlates with slower MEKi-induced FK, possibly due to a greater capacity to 'buffer' the accumulation of pro-death proteins like BIM. The ability to track FK over time in multiple independent populations was central to elucidating this relationship.

The pathway linking MAPK pathway inhibition to increased MCL1 levels was unclear. In our RNA-seq analysis we observed increased expression of several JUN-family immediate early genes, consistent with activation of the JNK pathway (Figure S5). This was intriguing as in other systems JNK1/2 can suppress apoptosis by phosphorylating and stabilizing MCL1 (Hirata et al., 2013; Kodama et al., 2009). We confirmed activation of the JNK pathway in response to MEKi treatment by RT-qPCR and Western blotting for JUN family members in parental A549N cells (Figure 5D,E). Moreover, we observed that inhibition of JNK function using the small molecule inhibitor JNKi VIII (Miura et al., 2018) inhibited JUN expression and phosphorylation, and specifically blocked MCL1 accumulation in response to MEKi treatment, without affecting BCL-xL or BIM levels (Figure 5E). Thus, inhibition of the MAPK pathway can cause of activation of the stress responsive JNK pathway and stabilization of anti-apoptotic MCL1 protein, impacting the kinetics of FK.

\section{Compound interactions alter MEKi-induced fractional killing over time}

In the clinic, few drugs are employed as single agents and it is therefore of interest to understand the impact of drug interactions specifically on FK (Palmer et al., 2019). We show, above, that it is possible to detect chemical interactions that 
enhance FK (e.g. MEKis + MCL1 inhibition, Figure 4F). Our ability to monitor FK in many populations in parallel suggested provided a means to search for modulators of FK more systematically. As proof-of-principle, we examined the effect on Pim-induced cell death of 261 structurally and functionally distinct compounds in A549N cells. The ability of all 261 compounds to modulate Piminduced cell death was computed using an analytic framework based on the Bliss model of drug interactions (Conlon et al., 2019). This dataset provided an opportunity to systematically assess how drug interactions impacted FK (Figure 6A). Strikingly, multiple ATP-competitive and allosteric mechanistic target of rapamycin (mTOR) inhibitors potently accelerated Pim-induced FK, both reducing Do and increasing $D_{R}$ by as much as five-fold (Figure 6B). In follow-up experiments we confirmed that two structurally and mechanistically distinct mTOR inhibitors, the ATP competitive inhibitor AZD8055 and the rapalog rapamycin, both accelerated MEKi-induced FK specifically, with no sensitization observed towards bortezomib (Figure 6C). These results indicate that it is possible to pinpoint drug interactions that specifically alter FK in a high-throughput manner.

Our finding that mTOR inhibition accelerated MEKi-induced FK was intriguing in light of evidence that mTOR signaling promotes MCL1 mRNA expression and post-translational MCL1 stability (Koo et al., 2015; Mills et al., 2008). Based on these findings, we hypothesized that mTOR inhibition accelerated MEKi-induced FK through by reducing MCL1 expression. However, mTOR inhibitors did not reduce basal MCL1 expression or prevent Pim treatment from increasing MCL1 protein levels in $A 549^{N}$ cells (Figure 6D). We confirmed that 
mTOR inhibitors blocked the phosphorylation of the canonical downstream mTOR targets RPS6 (both) and/or 4EBP1 (AZD8055 only) and did not alter the effect of Pim on BIM upregulation or BCL-xL downregulation (Figure 6D).

These results suggested that mTOR signaling might promote $\mathrm{FK}$ independent of effects on MCL1. To investigate further, we generated two clonal MCL1 gene disrupted cell lines, one (LOF1) that appeared to be a severe loss of function, and one (LOF2) that appeared to be a complete knockout, based on MCL1 protein expression and sensitivity to the MCL1 inhibitor S63845 (Figure $6 \mathrm{E}, \mathrm{F})$. Consistent with results obtained using the polyclonal CRISPR method (Figure S4K,L), MEKi-induced FK was substantially accelerated by clonal disruption of MCL1 (Figure 6E). Notably, mTOR inhibition enhanced MEKi-induced FK equivalently in the presence or absence of MCL1. This suggests that mTOR inhibition likely sensitizes to MEKi-induced FK independent of MCL1. These results demonstrate that it is possible to systematically search for and isolate compoundcompound interactions that specifically alter the kinetics of FK.

\section{DISCUSSION}

Heterogeneous cellular phenotypes within one population are common in nature, with drug-induced fractional killing in tumors being one clinically important manifestation (Bigger, 1944; Inde and Dixon, 2018; Niepel et al., 2009; Palmer et al., 2019). Quantifying population-level cell heterogeneity can be laborious, especially when tracking the fate of hundreds of individual cells within a single population. We find that population-level time-lapse measurements of live and 
dead cells enables FK to be effectively quantified without tracing individual cells. This enables the quantitative, large-scale analysis of FK in hundreds of populations in parallel in a single experiment. A limitation of this approach is that highthroughput time-lapse imaging remains less accessible than more traditional methods. However, we show that traditional bulk biochemical methods (e.g. CellTiter-Glo and AlamarBlue) suffer limitations that make them unsuitable for the precise quantification of FK between conditions.

Consistent with previous single-cell analyses of different individual populations (Miura et al., 2018; Paek et al., 2016; Roux et al., 2015; Spencer et al., 2009) we find that FK is fundamentally a kinetic phenomenon. At any given time, some fraction of cells within the population may be alive and others dead. Our findings make clear that at any given timepoint this fraction can vary substantially between lethal treatments and genetic backgrounds. It is important to note that for many lethal conditions all cells within the population would ultimately die, at some timepoint. What these methods enable is for the heterogeneity of cell death initiation between cells in population to be easily quantified and compared. In turn, this allows for the contribution of different molecular mechanisms to the kinetics of cell death to be specifically isolated. This contrasts with the majority of mechanistic studies, which seek only to arrive at a binary (yes/no) distinction concerning whether a given protein or mechanism contributes to a lethal process at any timepoint.

As a case study to search for molecular regulators of FK, we focused on inhibitors of the MAPK pathway, finding that MCL1 plays an important role in this 
context. MCL1 expression is inherently highly variable, likely due to the short halflife of MCL1 mRNA and the instability of the protein (Senichkin et al., 2020). Our pharmacological, imaging, and overexpression studies suggest that differences in the initiation of between cells in the population are linked to variation between cells in MCL1 protein expression, with the ability to accumulate higher levels of MCL1 associated with later onset of cell death within the population (Figure 6G). At the molecular level, this may relate to differences in the time it takes for the entire MCL1 pool within a given cell to be fully overcome by the expression of pro-death $\mathrm{BH} 3$ proteins like BIM. Notably, and unlike inhibition of BCL-xL, pharmacological or genetic inactivation of MCL1 'homogenizes' the response of individual cells to MAPK pathway inhibition, resulting in an effective acceleration of FK. That said, MCL1 inactivation does not render cells uniformly sensitive to death at the exact same time (i.e. $D_{R}$ remains under $10 \% \mathrm{~h}^{-1}$ ). One goal of future work is to define MCL1-independent mechanisms governing FK in response to MAPK pathway inhibition. Evidence from our compound interaction study suggests that one such mechanism involves mTOR, perhaps through regulation of a pro-apoptotic protein like BAD (Harada et al., 2001).

We find that the kinetics of FK differ substantially between drugs in the same genetic background and for the same drug in different backgrounds. Two lines of evidence suggest a single molecular mechanism is unlikely to account for these differences. First, proteins or mechanisms that regulate FK-like phenomena in other contexts, including p53, metabolism, and the cell cycle (Lagadinou et al., 2013; Miura et al., 2018; Paek et al., 2016; Roux et al., 2015), did not modulate FK 
in response to MEKis. Second, a single A549 population contains diverse subpopulations of cells with similar sensitivity to proteasome inhibition or nonapoptotic cell death induced by erastin2, but distinct sensitivities to MEKis. Thus, FK cannot be governed by a single unified mechanism. Further investigation of FK using the large-scale comparative approach presented here could help elucidate the constellation of different molecular mechanisms that regulate FK and provide new insights into this important form of phenotypic heterogeneity.

\section{$S T A R \diamond M E T H O D S$}

Detailed methods are provided in the online version of this paper and include the following:

- KEY RESOURCES TABLE

- LEAD CONTACT AND MATERIALS AVAILABILITY

- EXPERIMENTAL MODEL AND SUBJECT DETAILS

- Cell lines and Culture Conditions

$\circ$ Chemicals and Reagents

- METHOD DETAILS

- Measurement of cell viability using CellTiter-Glo and PrestoBlue

- Lentivirus generation and infection

- Generation of CRISPR/Cas9 knockout cell lines

- Isolation of clonal cell populations

- Cell seeding and compound treatment

- Doxycycline-inducible protein overexpression 
- CMV vector protein overexpression and rescue

- Time-lapse imaging, LED curve fitting and parameter extraction

- Kinase translocation reporter (KTR) analysis

- Cell metabolism and ROS analysis

- Western blotting

- RNA-seq

- Propidium iodide cell cycle profiling

○ Immunofluorescence imaging

○ Chemical library screening

- QUANTIFICATION AND STATISTICAL ANALYSIS

- DATA AND CODE AVAILABILITY

\section{SUPPLEMENTAL INFORMATION}

Supplemental information includes four figures and can be found with this article online.

\section{SUPPLEMENTAL INFORMATION}

Supplemental information includes four figures and can be found with this article online.

\section{ACKNOWLEDGEMENTS}


We thank L. Magtanong for comments, A. Gitler for plasmids and B. Stockwell for erastin. S.J.D. is supported by the NIH (1R01GM122923) and a Damon RunyonRachleff Innovation Award.

\section{AUTHOR CONTRIBUTIONS}

Conceptualization, Z.I., G.C.F., and S.J.D.; Methodology, Z.I., G.C.F.; Investigation, Z.I., G.C.F., and K.D.; Writing - Original Draft, Z.I. and S.J.D.; Writing - Review \& Editing, Z.I., G.C.F., and S.J.D.; Funding Acquisition and Supervision, S.J.D.

\section{DECLARATION OF INTERESTS}

S.J.D. is a member of the scientific advisory board of Ferro Therapeutics and is a consultant for Toray Industries.

\section{REFERENCES}

Berenbaum, M.C. (1972). In vivo determination of the fractional kill of human tumor cells by chemotherapeutic agents. Cancer chemotherapy reports 56, 563-571.

Bigger, J. (1944). Treatment of staphylococcal infections with penicillin by intermittent sterilisation. The Lancet 244, 497-500.

Boucher, M.J., Morisset, J., Vachon, P.H., Reed, J.C., Lainé, J., and Rivard, N. (2000). MEK/ERK signaling pathway regulates the expression of $\mathrm{Bcl}-2, \mathrm{Bcl}-\mathrm{X}(\mathrm{L})$, and $\mathrm{Mcl}-1$ and promotes survival of human pancreatic cancer cells. Journal of Cellular Biochemistry 79, 355-369. 
Cagnol, S., and Rivard, N. (2013). Oncogenic KRAS and BRAF activation of the MEK/ERK signaling pathway promotes expression of dual-specificity phosphatase 4 (DUSP4/MKP2) resulting in nuclear ERK1/2 inhibition. Oncogene 32, 564-576.

Chan, G.K.Y., Kleinheinz, T.L., Peterson, D., and Moffat, J.G. (2013). A simple high-content cell cycle assay reveals frequent discrepancies between cell number and ATP and MTS proliferation assays. PloS one 8, e63583.

Cragg, M.S., Jansen, E.S., Cook, M., Harris, C., Strasser, A., and Scott, C.L. (2008). Treatment of B-RAF mutant human tumor cells with a MEK inhibitor requires Bim and is enhanced by a $\mathrm{BH} 3$ mimetic. The Journal of clinical investigation 118, 3651-3659.

Fallahi-Sichani, M., Honarnejad, S., Heiser, L.M., Gray, J.W., and Sorger, P.K. (2013). Metrics other than potency reveal systematic variation in responses to cancer drugs. Nature chemical biology 9, 708-714.

Forcina, G.C., Conlon, M., Wells, A., Cao, J.Y., and Dixon, S.J. (2017). Systematic Quantification of Population Cell Death Kinetics in Mammalian Cells. Cell Systems $4,600-610$.

Harada, H., Andersen, J.S., Mann, M., Terada, N., and Korsmeyer, S.J. (2001). p70S6 kinase signals cell survival as well as growth, inactivating the pro-apoptotic molecule BAD. Proc Natl Acad Sci U S A 98, 9666-9670.

Hata, A.N., Yeo, A., Faber, A.C., Lifshits, E., Chen, Z., Cheng, K.A., Walton, Z., Sarosiek, K.A., Letai, A., Heist, R.S., et al. (2014). Failure to induce apoptosis via 
BCL-2 family proteins underlies lack of efficacy of combined MEK and PI3K inhibitors for KRAS-mutant lung cancers. Cancer research 74, 3146-3156.

Hirata, Y., Sugie, A., Matsuda, A., Matsuda, S., and Koyasu, S. (2013). TAK1-JNK axis mediates survival signal through Mcl1 stabilization in activated T cells. Journal of immunology (Baltimore, Md : 1950) 190, 4621-4626.

Inde, Z., and Dixon, S.J. (2018). The impact of non-genetic heterogeneity on cancer cell death. Critical reviews in biochemistry and molecular biology 53, 99114.

Kepp, O., Galluzzi, L., Lipinski, M., Yuan, J., and Kroemer, G. (2011). Cell death assays for drug discovery. Nature reviews Drug discovery 10, 221-237.

Kim, C., and Giaccone, G. (2018). MEK inhibitors under development for treatment of non-small-cell lung cancer. Expert opinion on investigational drugs 27, 17-30.

Kodama, Y., Taura, K., Miura, K., Schnabl, B., Osawa, Y., and Brenner, D.A. (2009). Antiapoptotic effect of c-Jun N-terminal Kinase-1 through Mcl-1 stabilization in TNF-induced hepatocyte apoptosis. Gastroenterology 136, 14231434.

Koo, J., Yue, P., Deng, X., Khuri, F.R., and Sun, S.-Y. (2015). mTOR Complex 2 Stabilizes Mcl-1 Protein by Suppressing Its Glycogen Synthase Kinase 3Dependent and SCF-FBXW7-Mediated Degradation. Molecular and cellular biology 35, 2344-2355. 
Lagadinou, E.D., Sach, A., Callahan, K., Rossi, R.M., Neering, S.J., Minhajuddin, M., Ashton, J.M., Pei, S., Grose, V., O\&apos;Dwyer, K.M., et al. (2013). BCL-2 inhibition targets oxidative phosphorylation and selectively eradicates quiescent human leukemia stem cells. Cell stem cell 12, 329-341.

Luciano, F., Jacquel, A., Colosetti, P., Herrant, M., Cagnol, S., Pages, G., and Auberger, P. (2003). Phosphorylation of Bim-EL by Erk1/2 on serine 69 promotes its degradation via the proteasome pathway and regulates its proapoptotic function. Oncogene 22, 6785-6793.

Marani, M., Tenev, T., Hancock, D., Downward, J., and Lemoine, N.R. (2002). Identification of novel isoforms of the $\mathrm{BH} 3$ domain protein Bim which directly activate Bax to trigger apoptosis. Molecular and cellular biology 22, 3577-3589.

Mateus, A., Gordon, L.J., Wayne, G.J., Almqvist, H., Axelsson, H., SeashoreLudlow, B., Treyer, A., Matsson, P., Lundbäck, T., West, A., et al. (2017). Prediction of intracellular exposure bridges the gap between target- and cell-based drug discovery. Proceedings of the National Academy of Sciences of the United States of America 114, E6231-E6239.

McQuin, C., Goodman, A., Chernyshev, V., Kamentsky, L., Cimini, B.A., Karhohs, K.W., Doan, M., Ding, L., Rafelski, S.M., Thirstrup, D., et al. (2018). CellProfiler 3.0: Next-generation image processing for biology. PLoS biology 16, e2005970. 
Meng, J., Fang, B., Liao, Y., Chresta, C.M., Smith, P.D., and Roth, J.A. (2010). Apoptosis induction by MEK inhibition in human lung cancer cells is mediated by Bim. PloS one 5, e13026.

Mills, J.R., Hippo, Y., Robert, F., Chen, S.M.H., Malina, A., Lin, C.-J., Trojahn, U., Wendel, H.-G., Charest, A., Bronson, R.T., et al. (2008). mTORC1 promotes survival through translational control of Mcl-1. Proceedings of the National Academy of Sciences of the United States of America 105, 10853-10858.

Miura, H., Kondo, Y., Matsuda, M., and Aoki, K. (2018). Cell-to-Cell Heterogeneity in p38-Mediated Cross-Inhibition of JNK Causes Stochastic Cell Death. Cell reports $24,2658-2668$.

Montero, J., Gstalder, C., Kim, D.J., Sadowicz, D., Miles, W., Manos, M., Cidado, J.R., Paul Secrist, J., Tron, A.E., Flaherty, K., et al. (2019). Destabilization of NOXA mRNA as a common resistance mechanism to targeted therapies. Nat Commun $10,5157$.

Nangia, V., Siddiqui, F.M., Caenepeel, S., Timonina, D., Bilton, S.J., Phan, N., Gomez-Caraballo, M., Archibald, H.L., Li, C., Fraser, C., et al. (2018). Exploiting MCL1 Dependency with Combination MEK + MCL1 Inhibitors Leads to Induction of Apoptosis and Tumor Regression in KRAS-Mutant Non-Small Cell Lung Cancer. Cancer discovery 8, 1598-1613. 
Niepel, M., Spencer, S.L., and Sorger, P.K. (2009). Non-genetic cell-to-cell variability and the consequences for pharmacology. Current opinion in chemical biology $13,556-561$.

Paek, A.L., Liu, J.C., Loewer, A., Forrester, W.C., and Lahav, G. (2016). Cell-toCell Variation in p53 Dynamics Leads to Fractional Killing. Cell 165, 631-642.

Palmer, A.C., Chidley, C., and Sorger, P.K. (2019). A curative combination cancer therapy achieves high fractional cell killing through low cross-resistance and drug additivity. Elife 8.

Pétigny-Lechartier, C., Duboc, C., Jebahi, A., Louis, M.-H., Abeilard, E., Denoyelle, C., Gauduchon, P., Poulain, L., and Villedieu, M. (2017). The mTORC1/2 Inhibitor AZD8055 Strengthens the Efficiency of the MEK Inhibitor Trametinib to Reduce the $\mathrm{Mcl}-1 /[\mathrm{Bim}$ and Puma] ratio and to Sensitize Ovarian Carcinoma Cells to ABT737. Molecular cancer therapeutics 16, 102-115.

Regot, S., Hughey, J.J., Bajar, B.T., Carrasco, S., and Covert, M.W. (2014). Highsensitivity measurements of multiple kinase activities in live single cells. Cell 157, 1724-1734.

Robert, C., Grob, J.J., Stroyakovskiy, D., Karaszewska, B., Hauschild, A., Levchenko, E., Chiarion Sileni, V., Schachter, J., Garbe, C., Bondarenko, I., et al. (2019). Five-Year Outcomes with Dabrafenib plus Trametinib in Metastatic Melanoma. The New England journal of medicine 381, 626-636. 
Roux, J., Hafner, M., Bandara, S., Sims, J.J., Hudson, H., Chai, D., and Sorger, P.K. (2015). Fractional killing arises from cell-to-cell variability in overcoming a caspase activity threshold. Molecular systems biology $11,803-803$.

Sale, M.J., Minihane, E., Monks, N.R., Gilley, R., Richards, F.M., Schifferli, K.P., Andersen, C.L., Davies, E.J., Vicente, M.A., Ozono, E., et al. (2019). Targeting melanoma's MCL1 bias unleashes the apoptotic potential of BRAF and ERK1/2 pathway inhibitors. Nat Commun 10, 5167.

Santos, L.C., Vogel, R., Chipuk, J.E., Birtwistle, M.R., Stolovitzky, G., and Meyer, P. (2019). Mitochondrial origins of fractional control in regulated cell death. Nature communications $10,1313-1310$.

Senichkin, V.V., Streletskaia, A.Y., Gorbunova, A.S., Zhivotovsky, B., and Kopeina, G.S. (2020). Saga of Mcl-1: regulation from transcription to degradation. Cell Death Differ 27, 405-419.

Sharma, S.V., Lee, D.Y., Li, B., Quinlan, M.P., Takahashi, F., Maheswaran, S., McDermott, U., Azizian, N., Zou, L., Fischbach, M.A., et al. (2010). A chromatinmediated reversible drug-tolerant state in cancer cell subpopulations. Cell 141, 6980.

Skipper, H.E. (1965). The effects of chemotherapy on the kinetics of leukemic cell behavior. Cancer Res 25, 1544-1550. 
Spencer, S.L., Gaudet, S., Albeck, J.G., Burke, J.M., and Sorger, P.K. (2009). Nongenetic origins of cell-to-cell variability in TRAIL-induced apoptosis. Nature 459, 428-432.

Spudich, J.L., and Koshland, D.E. (1976). Non-genetic individuality: chance in the single cell. Nature 262, 467-471.

Wu, P.H., Gilkes, D.M., Phillip, J.M., Narkar, A., Cheng, T.W., Marchand, J., Lee, M.H., Li, R., and Wirtz, D. (2020). Single-cell morphology encodes metastatic potential. Sci Adv 6, eaaw6938.

Zhao, Y., and Adjei, A.A. (2014). The clinical development of MEK inhibitors. Nature reviews Clinical oncology 11, 385-400.

\section{FIGURE LEGENDS}

Figure 1. Systematic investigation of fractional killing. (A) At a given drug dose and time, a fraction of cells within the population will be killed while others survive. (B) Overview of cell death analysis using time lapse imaging of population live (nuclear mKate2) and dead (SYTOX Green) cell over time. These data can be integrated into a single metric, the lethal fraction, representing overall population cell death. (C) Heatmap summaries of mKate2 positive (mKate2 ${ }^{+}$) live cell counts, SYTOX Green positive $\left(\mathrm{SG}^{+}\right)$dead cell counts, and integrated lethal fraction scores as a function of time (x-axis) and concentration ( $y$-axis) for ten compounds in $\mathrm{U}-2 \mathrm{OS}^{\mathrm{N}}$ cells. For the $\mathrm{mKate} 2^{+}$heatmaps, live cell counts were normalized to 1 
at time $=0$ and expressed on a $\log _{10}$ scale. Etop: etoposide, Cpt: camptothecin, Sts: staurosporine, Thap: thapsigargin, Tun: tunicamycin, Era: erastin, Pac, paclitaxel, Vinb: vinblastine. (D) Isolated live cell counts, dead cell counts (mKate2 ${ }^{+}$ or $\mathrm{SG}^{+}$objects $/ \mathrm{mm}^{2}$ imaged area; Obj./mm²) and corresponding lethal fraction (Let. frac.) scores over time, extracted from select conditions in C. The stars $\left(^{*}\right)$ indicate where live cell counts increase beyond the range of the $y$-axis scale. $(E$, $F)$. Lethal fraction scores over time for $U-2 \mathrm{OS}^{\mathrm{N}}(\mathrm{E})$ and $\mathrm{T}^{\mathrm{N}} \mathrm{G}^{\mathrm{N}}(\mathrm{F})$ cells exposed to four lethal compounds. (G, H). Extracted mean lethal fractions at select timepoints from the data presented in $E$ and $F$. Data are from three independent experiments and represent the mean $(C, G, H)$ or mean $\pm S D(D-F)$.

Figure 2. Quantification of time-dependent fractional killing. (A) Overview of cell death kinetic analysis using time-lapse imaging and curve fitting. Lethal fraction curves can be fit with a lag exponential death (LED) model that yields two key parameter values, $D_{0}$ and $D_{R}$, which reflect the timing of cell death onset and the maximum rate of cell death within the population, respectively (Forcina et al., 2017). (B) Treatments that trigger cell death with low between-cell heterogeneity will have high $D_{R}$ values, and vice versa, which can impact the interpretation of FK at any given early timepoint. (C) Extracted $D_{R}$ parameter values for LED curves fit to lethal fraction scores for a sub-set of the lethal compounds shown in Figure 1D and S1G. Kinetic parameter values were only computed for compound concentrations where the lethal fraction at $120 \mathrm{~h}$ exceeded 0.5 . Results are mean \pm SD from three independent experiments. (D) Representative population images 
over time for camptothecin (Cpt)-treated cells. Heterogeneity is especially apparent at the $48 \mathrm{~h}$ timepoint, where arrows indicate example live cells and arrowheads indicate example dead cells. Scale bar $=75 \mu \mathrm{m}$. (E) Traces of lethal fraction scores over time for 140 lethal compounds identified previously. (F) Extracted $D_{R}$ values for 139 lethal compounds from $E$ where it was possible to compute this parameter value. $(G) D_{R}$ values for compounds in $F$ broken down by compound class. $(\mathrm{H})$ Representative population images for select conditions from $\mathrm{G}$ to illustrate heterogeneity in cell death initiation throughout the population. Scale bar $=75 \mu \mathrm{m}$.

Figure 3. MEKis trigger cell death with high between-cell variability. (A) Outline of key RAS/MAPK pathway components highlighting inhibitors (orange) of MEK1/2 (i.e. MEKis) and ERK1/2. (B) Cell death in A549N cells summarized over time and MEKi concentration. (C) Cell death kinetic parameters for the data in B summarized over compound concentration. Note: parameters can only be computed with confidence for compound concentrations with lethal fraction $>\sim 0.2$. (D) Western blot for phosphorylated and total $E R K 1 / 2$ in $A 549^{N}$ cells. (E) Quantification of phospho-ERK1/2 and total ERK1/2 at different concentrations of pimasertib at two timepoints. (F) Data for ERK kinase translocation reporter (KTR) in $\mathrm{A}^{4} \mathrm{~N}^{\mathrm{N}}$ cells in response to MEKi treatment over time. ERK KTR response to an unrelated lethal compound, bortezomib, is shown as a control. Death onset for lethal conditions (from B,C for MEKis and not shown for Btz) is shown by a dashed line (Do) (G) Cell death in A549N cells summarized over time and concentration for 
the ERK inhibitor (ERKi) SCH772984. Cell death kinetic parameter values are shown for cells treated with $5 \mu \mathrm{M}$ SCH772984. (H) Expression of the MAPK pathway target DUSP4 in response to SCH772984. (I) Quantification of experiment outlined in $\mathrm{H}$, for three individual experiments. (J) Normalized live cell (mKate2 ${ }^{+}$ objects) counts within the same population of cells over two cycles of pimasertib (Pim, $5 \mu \mathrm{M}$, grey shaded area) addition with an intervening period of regrowth in the absence of drug (white area). All data are from at least three independent experiments, and represented as the mean $(B, G)$, mean $\pm 95 \%$ C.I. $(C)$, or mean $\pm \operatorname{SD}(E, F, I, J)$

Figure 4. Variable Mcl-1 expression correlates with MEKi-induced FK. (A) Summary of RNA sequencing analysis of cells treated with pimasertib at cytotoxic (5 $\mu \mathrm{M}, \mathrm{A} 549$ and Calu-6) and cytostatic (non-cytotoxic) (0.5 $\mu \mathrm{M}$ in A549) doses. RNA was obtained for analysis from two independent experiments and FKPM values for each gene were averaged prior to further analysis. (B) GO analysis for the 555 significantly altered death-associated genes. (C) Inhibitors (bold text) block the function of BCL-2-family proteins to induce apoptosis. (D) Cell death over time in $A 549^{N}$ cells co-treated with MEKis and the BCL-xL inhibitors ABT-737 or A1155463 (both $5 \mu \mathrm{M}$ ). (E) Cell death kinetic parameters for treatments in $\mathrm{D}$. (F) Cell death over time in $A 549^{N}$ cells co-treated with MEKis or bortezomib (Btz) and the MCL1 inhibitor S63845 (5 $\mu \mathrm{M})$. (G) Cell death kinetic parameters for treatments in $F .(H)$ Mean single cell fluorescence intensity (M.F.I.) for MCL1 and BCL-xL in individual $A 549^{N}$ cells determined by immunofluorescence at $48 \mathrm{~h} \pm \operatorname{Pim}(5 \mu \mathrm{M})$. 
Coefficient of variation (CV) is indicated. (I) MCL1 M.F.I. over time in A549 ${ }^{\mathrm{N}}$ cells treated as indicated. Coefficient of variation (CV) is shown for all conditions, and ranges (min-max) are shown for the $96 \mathrm{~h}$ sample. For $\mathrm{H}$ and $\mathrm{I}$, at least 115 individual cells are quantified per condition from multiple independent microscopic fields, and median and interquartile ranges are indicated. (J) Expression of MCL1 in $A 549^{\mathrm{N}}$ cells transduced with CMV-Empty and CMV-MCL1 lentivirus. (K) Cell death over time \pm MCL1 overexpression, as in J. (L) $D_{R}$ values computed from lethal fraction curves in $\mathrm{K}$ for MEKis. Results are from three independent experiments and represent the mean $\pm S D(D, F, K)$ or the mean $\pm 95 \%$ C.I. (E, G, L).

Figure 5. Heterogeneous MCL1 expression correlates with death sensitivity. (A) Overview of the strategy used to isolate clonal populations of $A 549^{\mathrm{N}}$ cells. (B) Cell death over time for individual clonal populations examined in parallel. Each independent clone was derived from a single cell, expanded, and tested a single time. Key clones analyzed at the protein level in $\mathrm{C}$ are numbered. (C) Expression of key apoptotic proteins in low and high sensitivity clones. (D) RT-qPCR analysis in $A 549^{N}$ cells of selected IEGs. Individual datapoints represent individual experiments, and mean values are indicated by the horizontal bar. (E) Western blot of $A 549^{N}$ cells. Pim and JNKi VIII were both used at $5 \mu \mathrm{M}$.

Figure 6. High-throughput analysis of drug interactions impacting fractional killing. (A) A drug-drug interaction screen in Pim-treated A549N cells. Cells were 
co-treated $\pm 5 \mu \mathrm{M}$ Pim plus a library of 261 bioactive compounds and controls. Data on the $y$-axis represent deviations of the observed normalized area under the curve (nAUC) value from the expected nAUC value for each library compound in combination with Pim as calculated using the Bliss model of drug independence (see Methods). The screen was performed three separate times and the results represent mean \pm SD. (B) Kinetics of cell death computed for the top 20 enhancers of Pim-induced cell death. mTOR inhibitors are indicated in green. (C) Cell death over time for the indicated combinations. Rapamycin was used at $50 \mathrm{nM}$, and AZD8055 at $500 \mathrm{nM}$. Mean $D_{R}$ values were computed from lethal fraction curves and are indicated. (D) Analysis of protein expression by Western blotting \pm Pim (5 $\mu M)$, rapamycin (50 nM) or AZD8055 (500 nM) at 48 h. (E) Cell death over time in Control and two independent MCL1 loss of function clones (LOF1/2). (F) Protein expression in Control, and MCL1 LOF1 and LOF2 cell lines. Compound treatment was for 48 h. (G) Model expressing how variability in MCL1 expression links to variable membrane permeabilization (i.e. cell death) over time. Data are from three independent experiments and represent mean $\pm 95 \%$ C.I. (B) or mean \pm SD $(C, E)$.

\section{$S T A R \diamond M E T H O D S$}

\section{Lead Contact for Materials Availability}

Further information and requests for resources and reagents should be directed to and will be fulfilled by the Lead Contact, Scott Dixon (sjdixon@stanford.edu). 


\section{Experimental Model and Subject Details}

\section{Cell lines and culture conditions}

The following cell lines were obtained from ATCC (Manassas, VA): A549 (CCL185, sex: male), Calu-6 (HTB-56, sex: female), NCl-H1299 (CRL-5803, sex: male), NCl-H2291 (CRL-5939, sex: male), T98G (CRL-1690, sex: male), U-2 OS (HTB96, sex: female) and HEK 293T cells (CRL-3216, sex: female). Cell lines stablyexpressing nuclear-localized mKate2 (denoted by the superscript ' $N$ ') were generated by infection with lentivirus (Cat\# 4625, Essen BioScience, Ann Arbor, MI) followed by puromycin $(10 \mu \mathrm{g} / \mathrm{mL}$, Cat\# A11138-03, Life Technologies, Carlsbad, CA) selection for three days. For kinase translocation reporter (KTR) and polyclonal CRISPR cell lines described below, mKate2-expressing cell lines were generated with a bleomycin-selectable lentiviral construct (Cat\# 4627, Essen BioScience) to allow subsequent infection with puromycin-selectable KTR constructs. After infection with bleomycin-selectable lentivirus, cell lines were sorted to isolate mKate2-positive cells using a FACSAria II Fluorescence Activated Cell Sorter (BD Biosciences, San Jose, CA) at the Stanford Shared FACS Facility.

Cell lines were cultured in an appropriate base media supplemented with 10\% fetal bovine serum (Cat\# 26140-079, Thermo Fisher Scientific) and 1\% penicillin/streptomycin (Cat\# 105070-063, Life Technologies). Base media used was DMEM (Cat\# MT-10-013-CV, Thermo Fisher Scientific) for A549, Calu-6, NCIH1299 (H1299), T98G, and HEK293T, RPMI (Cat\# SH30027FS, Thermo Fisher Scientific) for NCl-H2291, and McCoy's 5A (Cat\# MT-10-050-CV, Thermo Fisher Scientific) for $\mathrm{U}-2$ OS. Cell lines were cultured in incubators at $37^{\circ} \mathrm{C}$ and $5 \% \mathrm{CO}_{2}$. 
For passaging, cells were rinsed with HBSS (Cat\# 14025-134, Life Technologies), dissociated with $0.25 \%$ trypsin-EDTA (Cat\# SH3004201, Thermo Fisher Scientific), quenched with the corresponding complete media, and counted using a Cellometer Auto T4 Bright Field Cell Counter (Nexcelom, Lawrence, MA). Upon counting, cells were subsequently seeded for experiments as described below.

\section{Chemicals and reagents}

Camptothecin (Cat\# S1288), vinblastine (Cat\# S1248), pimasertib (Cat\# S1457), trametinib (Cat\# S2673), ABT-737 (Cat\# S1002), A-1155463 (Cat\# S7800), Nutlin-

3 (Cat\# S1061) were purchased from Selleck Chemicals (Houston, TX). Bortezomib (Cat\# NC0587961), etoposide (Cat\# ICN19391825), MG-132 (Cat\# 17-485), and Q-VD-OPh (Cat\# OPH00101M) were purchased from Thermo Fisher Scientific. N-acetylcysteine (Cat\# A8199), thapsigargin (Cat\# T9033), tunicamycin (Cał\# T7765), paclitaxel (Cał\# T7191), JNK Inhibitor VIII (Cat\# 420135), 2deoxyglucose (Cat\# D8375), oligomycin (Cat\# O4876), and cycloheximide (Cat\# C7698) were obtained from Sigma-Aldrich (St. Louis, MO). S63845 (Cat\#21131) was obtained from Cayman Chemical (Ann Arbor, MI). Staurosporine (Cat\# A8192) was obtained from ApexBio (Houston, TX). Erastin was the kind gift of Brent Stockwell (Columbia University). Erastin2 (compound 35MEW28 in (Dixon et al., 2014)) and ML162 (CAS: 1035072-16-2) were synthesized by Acme Bioscience (Palo Alto, CA). Chemical screening was conducted as described below; the library of 261 bioactive compounds was obtained from Selleck Chemicals (Cat\# L2000). 


\section{Method Details}

\section{Measurement of cell counts and cell viability using CellTiter-Glo and PrestoBlue}

U-2 OS $^{N}$ and T98G $^{N}$ cells were seeded into parallel 384-well plates at a concentration of 1,500 cells/well, briefly spun at 500 RPM to settle cells to the bottom of plates, and then incubated for $24 \mathrm{~h}$ in a tissue culture incubator prior to the start of the experiment. The next day, $4 \mu \mathrm{L}$ of $10 \mathrm{X}$ drug stock prepared in media was added to $36 \mu \mathrm{L}$ of fresh media to a final concentration of $1 \mathrm{X}$. At $72 \mathrm{~h}$, both plates were scanned for mKate2 positive objects (i.e. live cells) using an IncuCyte imaging system (Essen BioScience) and the imaging parameters described in Table S1. Then immediately after the scans, one plate was subjected to CellTiterGlo (CTG, Promega, Cat\# G7570) analysis and the other to Presto Blue (PB, Thermo Fisher Scientific, Cat\# A13262) analysis using the above commercially available reagents. For CTG analysis, cells were lysed by addition of $40 \mu \mathrm{L}$ of CellTiter-Glo reagent for two min while shaking. Cells were allowed to equilibrate for $10 \mathrm{~min}$ post-lysis followed by luminescence reading using a Cytation3 multimode plate reader (BioTek, Winooski, VT, USA) set to luminescence, optics position $=$ top, gain $=135$. For PB analysis, $10 \mu \mathrm{L}$ of $5 \mathrm{X}$ PB reagent was added to each well and the plate was then allowed to incubate at $37^{\circ} \mathrm{C}$ and $5 \% \mathrm{CO}_{2}$ for 30 min, followed by fluorescence reading using a Cytation3 multimode plate reader (BioTek, Winooski, VT, USA) set to ex/em 560/590, optics position = bottom, gain $=75$. 


\section{Lentivirus generation and infection}

For generation of lentivirus, HEK293T cells were seeded at 300,000 cells per well in six well plates (Cat\# 07-200-83, Thermo Fisher Scientific) one day before transfection. Plasmids for lentiviral transduction were transfected into HEK293T cells along with lentiviral packaging plasmids pCMV-VSV-G, pMDLg/pRRE, and pRSV-Rev (obtained from Dr. Michael Bassik, available via Addgene as Cat\# 8454, 12251, and 12253). Transfection was conducted using PolyJet Transfection Reagent (Cat\# SL100688, SignaGen Laboratories, Rockville, MD) according to manufacturer instructions, using a plasmid mix of .25 $\mu \mathrm{g}$ pCMV-VSV-G, $0.25 \mu \mathrm{g}$ pMDLg/pRRE, $0.25 \mu \mathrm{g}$ pRSV-Rev, and $0.75 \mu \mathrm{g}$ of the appropriate transfer plasmid. Lentivirus-containing supernatant from the transfected cells was harvested 48 and 72 hours after transfection and filtered through a $0.45 \mu \mathrm{m}$ Millex filter (Cat\# SLHV033RS, EMD Millipore, Burlington, MA) using a $10 \mathrm{~mL}$ syringe (Cat\# 14-81730, Thermo Fisher Scientific). Filtered lentivirus was stored at $-80^{\circ} \mathrm{C}$ or used immediately. For infection, cell lines were seeded a day before infection in 12 well plates (Cat\# 07-200-82, Thermo Fisher Scientific) to be approximately 50\% confluent on the day of infection. On the day of infection, supernatant was removed from the cells and replaced with $500 \mu \mathrm{L}$ of lentivirus-containing media and $500 \mu \mathrm{L}$ of polybrene (Cat\# H9268-5G, Sigma-Aldrich, St. Louis, MO) diluted to a final concentration of $16 \mu \mathrm{g} / \mathrm{mL}$ in the appropriate complete media. Selection with the appropriate antibiotic was begun after two days.

\section{Generation of CRISPR/Cas9 knockout cell lines}


Two methods were used to generate CRISPR/Cas9 knockout cell lines, one yielding polyclonal knockout lines and the other clonal knockout cell lines. Polyclonal knockout cell lines were generated by lentiviral infection of cell lines with the lentiCas9-Blast plasmid and an MCL1 sgRNA-expressing plasmid. lentiCas9-Blast was a gift from Feng Zhang (Addgene plasmid \#52962; RRID: Addgene_52962). sgRNA expressing plasmids were produced by cloning sgRNA oligonucleotides with the appropriate adaptor sequences (see Table S2) into plasmid pMCB306 after digesting the plasmid with restriction enzymes BstXI and Bpu1120I (Cat\# FD1024, FD0094, Thermo Fisher Scientific). pMCB306 was a gift from Michael Bassik (Addgene plasmid \#89360; RRID: Addgene_89360). After infection and antibiotic selection (10 $\mu \mathrm{g} / \mathrm{mL}$ blasticidin or puromycin for three days), knockout cell lines were validated by Western blot.

Clonal CRISPR/Cas9 knockout cell lines were generated as described previously (Cao et al., 2019). Briefly, sgRNA expressing plasmids were produced by cloning sgRNA oligonucleotides with the appropriate adaptor sequences (see Table S2) into plasmid spCas9-2A-EGFP (PX458). spCas9-2A-EGFP (PX458) was a gift from Feng Zhang (Addgene plasmid \#48138; RRID: Addgene_48138). Knockout cell lines were generated from mKate2-expressing A549 cells generated with a bleomycin-selectable lentiviral construct, allowing for subsequent rescue using a puromycin-selectable construct. Cells were seeded and transfected with the sgMCL1-expressing plasmid in a 6 well plate using Lipofectamine LTX transfection reagent (Cat\# 15338030, Thermo Fisher Scientific) according to manufacturer's instructions. 2 days after transfection, single cells were isolated 
and sorted into a 96 well plate using an Influx Special Order fluorescence activated cell sorter (BD Biosciences, San Jose, CA) at the Stanford Shared FACS Facility. Cells were sorted into DMEM media supplemented with $30 \%$ fetal bovine serum (Cat\# 26140-079, Thermo Fisher Scientific) and 1\% penicillin/streptomycin (Cat\# 105070-063, Life Technologies). Clones were monitored and expanded to larger formats over the following 4 weeks, then validated for MCL1 knockout by Western blot.

\section{Isolation of clonal cell populations}

Single-cell clones were isolated and expanded from mKate2-expressing A549 cells. Low passage cells were trypsinized and brought to the Stanford Shared FACS facility for single cell sorting as described for CRISPR clone sorting above.

Two sets of twelve clones were passaged into new 96 well plates on days 23 and 25 after sorting. Each set of clones was treated with lethal drugs the day after seeding and monitored by Incucyte for 144 hours. Clones with insufficient cell number or heterogeneous expression of mKate2 were excluded from analysis. When seeded for drug treatment, clones were also expanded to obtain cell lysates for protein expression analysis. Cells were harvested and lysed for Western Blotting as described below, and protein expression was compared across clones.

\section{$\underline{\text { Cell seeding and compound treatment }}$}

Experiments measuring death after treatment with MEK inhibitors (or other lethal compounds), either alone or in combination with modulators (e.g. CHX, Q-VD- 
OPh, or Bcl-2 family inhibitors), were conducted as follows. Cells were seeded one day prior to drug addition in tissue culture treated clear-bottom 96- or 384-well plates (Fisher Scientific Cat\# 07-200-588, 07-201-013). Appropriate cell seeding density was determined for each cell line to ensure seeding dense enough for cells to proliferate normally and sparse enough to minimize death due to overcrowding before the end of the experiment. On the day of treatment, drugs were diluted to final doses in the appropriate cell culture media noted above. Seeding media was removed from the plate and replaced with drug-containing media. For experiments to be analyzed by STACK, 20 nM SYTOX Green dye (Life Technologies, Cat\# S7020) was included in the treatment media, and drug treated plates of cells were imaged every $4 \mathrm{~h}$ using an IncuCyte. Images were analyzed automatically as described below. For drug cycling experiments, cells were seeded in 384-well plates. On the day of drug removal, a multichannel pipette was used to remove the drug-containing media and wash once with normal media before adding normal media to the wells for the drug-untreated period.

\section{Doxycycline-inducible protein overexpression}

To generate doxycycline-inducible cell lines, cells were infected with lentivirus carrying the pLenti CMV rtTA3 Blast (w756-1) plasmid and selected with blasticidin (Cat\# A1113902, Thermo Fisher Scientific). Genes of interest were cloned into the pLenti CMVTRE3G eGFP Neo (w821-1) plasmid using a Gibson Assembly Master Mix kit (Cat\# E2611S, New England Biolabs, Ipswich, MA). pLenti CMV rtTA3 Blast (w756-1) and pLenti CMVTRE3G eGFP Neo (w821-1) were gifts from Eric 
Campeau (Addgene plasmids \#26429 and \#27569; RRIDs: Addgene_26429 and Addgene_27569). BCL2L1 (Bcl-xL) and both wild type and G156E-mutant $B C L 2 L 11$ (BIM) open reading frames for Gibson Assembly were obtained as custom synthesized gBlocks from Integrated DNA Technologies (Coralville, IA). Lentivirus was generated as described above and rtTA-expressing cell lines were infected and subsequently selected with $10 \mu \mathrm{g} / \mathrm{mL}$ Geneticin (Thermo Fisher Scientific, Cat\# 11811-031); complete selection with Geneticin required three passages in antibiotic. An uninfected control population was treated with Geneticin and passaged in parallel to ensure complete selection.

\section{$\underline{C M V}$ vector protein overexpression and rescue}

CMV overexpression of MCL1 and rescue of MCL1 ${ }^{\mathrm{KO}}$ cells was carried out using the pLenti CMV Puro DEST backbone. pLenti CMV Puro DEST (w118-1) was a gift from Eric Campeau \& Paul Kaufman (Addgene plasmid\# 17452; RRID: Addgene_17452). The open reading frame for MCL1 was obtained as a gift from Dr. Aaron Gitler as a pDONR plasmid from the human ORFeome. The MCL1 ORF was cloned into the pLenti CMV vector using a Gateway LR Clonase II kit (Cat\# 11791-020, Thermo Fisher Scientfic, Waltham, MA). The resulting plasmid is missing a stop codon; site-directed mutagenesis was carried out using the Q5 SiteDirected Mutagenesis Kit (New England Biolabs, Cat\# E0554S) to introduce a stop codon. Further site-directed mutagenesis was conducted to introduce phosphosite mutations for comparative rescue experiments in MCL1 KO cells. Mutagenesis primers are listed in Table S2. Lentivirus was generated as described above, 
generating virus with both the CMV-MCL1 wild type and mutant plasmids and the control backbone plasmid that did not undergo Gateway recombination. Cell lines were infected with the harvested virus, and infected cells were selected with 5 $\mu \mathrm{g} / \mathrm{mL}$ puromycin for three days.

\section{Time-lapse imaging, LED curve fitting and parameter extraction}

Image analysis was conducted using Incucyte Zoom software (Essen BioScience). Image analysis parameters were optimized for each cell line; parameters are listed in Table S1. Lethal fraction scoring, LED curve fitting and parameter extraction were carried out as described previously (Forcina et al., 2017). Red and green object counts (as quantified according to the parameters in Table S1) were used to the compute the lethal fraction at each timepoint and then using Prism 7 software (GraphPad, San Diego, CA), lethal Fraction curves were fit using the "Plateau followed by one-phase association" function to obtain an LED fit. Do (corresponding to $\mathrm{X} 0$ in Prism) and $\mathrm{D}_{\mathrm{R}}$ (corresponding to $\mathrm{K}$ in Prism) values were extracted from the successful curve fits. For parameter analysis in Figure 2, only lethal compound conditions yielding average lethal fraction scores $>0.5$ across all three independent experiments were examined.

\section{Kinase translocation reporter (KTR) analysis}

Kinase translocation reporter (KTR) cell lines were generated by lentiviral transduction of the pLentiCMV Puro DEST ERKKTRClover and pLentiPGK Puro DEST p38KTRClover plasmids (gift of Dr. Markus Covert, obtained via Addgene, 
Cat\# 59150, 59152). Infected cells were selected with $10 \mu \mathrm{g} / \mathrm{mL}$ puromycin for 3 days. For drug treatment experiments, periodic IncuCyte imaging started the day after seeding and continued for 24 hours before drug addition to establish an untreated baseline. No more than $30 \mathrm{~min}$ before the $24 \mathrm{~h}$ timepoint, seeding media was removed from the cells and drug-containing media was added to the plate. To analyze the collected images, Zoom analysis parameters were modified as listed in Table S1. KTR reporter was detected in the green channel in lieu of SYTOX Green in these experiments. mKate2 signal marked cell nuclei, and cells in which the KTR reporter translocated to the nucleus produced a dual-positive overlap signal that was quantified in the software.

\section{Cell metabolism and ROS analysis}

For analysis of glycolytic and oxidative metabolism upon drug treatment, A549N cells were seeded in normal media in Seahorse xFP plates (Cat\# 103022-100, Agilent Technologies, Santa Clara, CA) $24 \mathrm{~h}$ prior to conducting the assay. Sensor cartridges were also hydrated on the preceding day. On the day of the assay, cells were washed with complete Seahorse XF media (Cat\# 103334-100, Agilent Technologies) supplemented to final concentrations of $25 \mathrm{mM}$ glucose, $1 \mathrm{mM}$ pyruvate, and $4 \mathrm{mM}$ glutamine and adjusted to $\mathrm{pH}$ 7.4. After washing twice and replacing media with complete XF media, plates were imaged by IncuCyte to obtain cell counts for normalization and the plate was incubated in a non-CO2 incubator for one hour to de-gas. 10X solutions of drugs for injection (oligomycin, 2-DG, and ethanol vehicle control) were loaded into the sensor cartridge, and the 
cell plate and sensor cartridge were inserted into a Seahorse xFP Analyzer (Agilent Technologies) to obtain extracellular acidification rate (ECAR) and oxygen consumption rate (OCR) metrics. ECAR and OCR values were measured automatically approximately every 6 minutes; after four baseline measurements, drugs were injected from the cartridge and metabolic parameters were measured continuously over the remainder of the experiment.

For FACS analysis of ROS levels, cells were trypsinized and resuspended in HBSS containing $20 \mathrm{uM} \mathrm{H}_{2}$ DCFDA (Thermo Fisher Scientific, Cat\# D-399). Cells were incubated in a $37^{\circ} \mathrm{C}, 5 \% \mathrm{CO}_{2}$ incubator for 30 min to stain, then spun down at $1000 \mathrm{rpm}$ for $5 \mathrm{~min}$. $\mathrm{H}_{2}$ DCFDA containing supernatant was aspirated, and the pellet of stained cells was resuspended in HBSS and strained through a $35 \mu \mathrm{m}$ mesh filter into a test tube (Corning, Cat\# 352235) for sorting. Cells were sorted on a FACSAria II Fluorescence Activated Cell Sorter (BD Biosciences, San Jose, CA) at the Stanford Shared FACS Facility. The top and bottom $5 \%$ of cells based on $\mathrm{H}_{2}$ DCFDA were sorted into DMEM, counted, and seeded in 384 well plates prepared with diluted drugs before the sort. IncuCyte imaging began the following day and images were acquired once every $24 \mathrm{~h}$.

\section{Western blotting}

Cells for Western blot analysis were treated in 6 well plates (Thermo Fisher Scientific, Cat\# 07-200-83) or $10 \mathrm{~cm}$ dishes (USA Scientific, Ocala, FL, Cat\# CC7682-3394). At the time of harvest, treatment media was removed, and cells were washed with ice cold HBSS and detached with cell lifters (Fisher Scientific, 
Cat\# 07-200-364). Detached cells in HBSS were spun down at 1000 rpm for 5 min, then supernatant was removed, and the remaining pellets were frozen overnight at $-80^{\circ} \mathrm{C}$. NP-40 buffer (1\% NP-40 detergent, $50 \mathrm{mM}$ Tris- $\left.\mathrm{Cl} \mathrm{pH} 8.0,150 \mathrm{mM} \mathrm{NaCl}\right)$ was used for lysis. NP-40 buffer was supplemented with protease/phosphatase inhibitor cocktail (Cell Signaling Technology, Danvers, MA, Cat\# 5872S) and used to lyse frozen pellets. Lysis proceeded for $45 \mathrm{~min}$ on ice, then samples were sonicated for 10 pulses of 1 second each at 50\% amplitude with a Fisherbrand Sonic Dismembrator (Fisher Scientific, Cat\# FB120110). Lysates were centrifuged for $15 \mathrm{~min}$ at $12,700 \mathrm{rpm}$ to remove debris, then protein concentration was measured by BCA assay kit (Thermo Fisher Scientific, Cat\# 23252).

Lysates were combined with Bolt sample buffer and reducing agent (Thermo Fisher Scientific, Cat\# B0007, B0009) and heated for 10 min at $70^{\circ} \mathrm{C}$. Prepared samples were loaded onto Bolt $4-12 \%$ gradient gels (Thermo Fisher Scientific, Cat\# BG04120BOX) and run for 1 hour $45 \mathrm{~min}$ at $100 \mathrm{mV}$. Protein from the finished gel was transferred to a nitrocellulose membrane using an iBlot 2 Transfer stack (Invitrogen, Cat\# IB23002). Membranes were washed in Odyssey Blocking buffer (LI-COR Biosciences, Lincoln, NE) at room temperature for 1 hour, then incubated in primary antibody mixture overnight at $4^{\circ} \mathrm{C}$. Primary antibody incubation was followed by three, seven min washes in Tris-Buffered Saline $+0.1 \%$ Tween (TBS-T), then a 45 min room temperature incubation in secondary antibody mix. Membranes were washed three more times in TBS-T before imaging on an Odyssey CLx imaging system (LiCOr Biosciences). In cases where antibodies against both the phopho and total protein were used, both forms of the protein 
were blotted sequentially on the same membrane. The phosphorylated version of the protein was blotted first; after imaging, the membrane was stripped with a 20 min wash in NewBlot Nitro Stripping Buffer followed by three TBS-T washes. Membranes were then reprobed by the same protocol using an antibody mix targeting the total protein.

\section{$\underline{R N A-s e q}$}

RNA was harvested from A549 cells grown in six-well dishes. 150,000 cells were seeded into each well. The next day, cells were treated with either vehicle control (DMSO), a cytostatic, non-lethal concentration of pimasertib $(0.5 \mu \mathrm{M})$ or a cytotoxic, lethal concentration of pimasertib $(5 \mu \mathrm{M})$. Calu- 6 cells were seeded at 300,000 cells per well and the next day treated with DMSO or Pim $(5 \mu M)$. Treatments were carried out for $96 \mathrm{~h}$ prior to cell harvest. In vehicle-treated conditions, cells were split 1:8 after 24 hours of treatment to prevent overgrowth. Note: for lethal conditions (i.e. $5 \mu \mathrm{M}$ Pim), treatment resulted in $\sim 50 \%$ cell death at the time of cell harvest. At the time of harvest, treatment media was removed, and cells were washed with ice cold HBSS (to remove debris) and detached with cell lifters. Detached cells were pelleted (1000 rpm x 5 min), the HBSS supernatant was removed, and the cell pellets frozen at $-80^{\circ} \mathrm{C}$ overnight. The next day, cells were lysed and RNA extracted using a Qiashredder Kit and RNeasy Plus Mini Kit (Qiagen, Cat\# 796554, 74134). Purity, concentration, and integrity of RNA were assessed by NanoDrop Spectrophotomer (Thermo Fisher Scientific) and by Eukaryote Total RNA Nano chip analysis on a Bioanalyzer (Agilent) at the Stanford 
Protein and Nucleic Acid Facility. By Bioanalyzer, the RNA Integrity Number for each sample met a threshold of at least 6.8, and NanoDrop 260/280 and 260/230 ratios met a threshold of at least 1.95. After quality control, samples were shipped on dry ice to Novogene (Sacramento, CA) for library generation and 20M read PE150 sequencing on an Illumina HiSeq 4000 platform. Bioinformatic analysis was performed by Novogene. Reads with adaptor contamination, $>10 \%$ uncertain nucleotides, or $>50 \%$ nucleotides with base quality $<20$ were filtered out, and the remaining clean reads (at least $98 \%$ of reads in all conditions) were aligned to the reference genome using Tophat v2.0.12. At least $91 \%$ of clean reads were successfully mapped in all conditions. Pearson correlations between biological replicates yielded $\mathrm{R}^{2}$ values above 0.98 in all conditions. Gene expression analysis was performed using DESeq 1.10.1; we isolated all gene sequences that were significantly altered (adjusted $P$ value $<0.05$ ).

\section{Propidium iodide cell cycle profiling}

Cell cycle profiling of A549 cells was performed after treatment with drugs in a 6 well plate as described above. At the end of drug treatment, cells were washed with HBSS, trypsinized, and quenched, keeping the drug treatment media and HBSS wash for each condition to avoid loss of any loosely adherent dividing cells. Cells from each condition were spun down ( $500 \times \mathrm{g}, 5 \mathrm{~min})$, resuspended in HBSS for one wash, then spun down again. Each pellet was resuspended in $400 \mu \mathrm{L}$ HBSS, then $800 \mu \mathrm{L}$ ice cold $100 \%$ ethanol was added for fixation. Cells were fixed at 4 degrees $C$ for at least 1 hour and up to 3 weeks. When ready to be stained, 
fixed cells were equilibrated to room temperature, then pelleted and resuspended in HBSS containing $50 \mu \mathrm{g} / \mathrm{mL}$ propidium iodide (Thermo Fisher Scientific, Cat\# P3566) and $500 \mathrm{U} / \mathrm{mL}$ RNAse A (Thermo Fisher Scientific, Cat\# EN0531). Staining was carried out for 30 minutes at 37 degrees $C$, then cells were spun down, resuspended in HBSS for one wash, then spun down again. For analysis, cells were resuspended in HBSS and run on a FACSCalibur flow cytometer (BD Biosciences). Histograms of signal from the FITC channel were analyzed in FlowJo 10.6.1, using the Cell Cycle platform to estimate percentages of cells in each cell cycle phase based on propidium iodide signal.

\section{Immunofluorescence imaging}

A549 cells were seeded in 12-well plates for immunofluorescence and treated with drugs as described above. When seeding for immunofluorescence, $12 \mathrm{~mm}$ round glass \#1.5 coverslips (Electron Microscopy Sciences, Hatfield, PA, Cat\# 7223001) coated with poly-D-lysine (Sigma-Aldrich, Cat\# P0899) were placed in each well of the 12 well plate, allowing cells to adhere to the coverslips before treatment. Once drug treatment was complete, drug-containing media was removed and cells were washed once with PBS. PBS was removed and replaced with ice cold methanol (Fisher Scientific, Cat\# A935-4) to fix cells; fixation was carried out at $20^{\circ} \mathrm{C}$ for at least one hour and up to $72 \mathrm{~h}$. To stain fixed cells, methanol was removed and replaced with PBS for one wash, then coverslips were blocked in PBS containing $3 \%$ bovine serum albumin (Gemini Bio-Products, West Sacramento, CA, Cat\# 700-100P) 0.1\% Triton X-100 (Sigma-Aldrich, Cat\# X-100), 
and $0.02 \%$ sodium azide (Sigma-Aldrich, Cat\# S2002) (PBS-BT). Blocking was carried out for 1 hour at room temperature or overnight at $4^{\circ} \mathrm{C}$. After blocking, coverslips were transferred to a light-blocking, parafilm-coated humid chamber for staining. All staining solutions were made in PBS-BT, and all subsequent steps were carried out at room temperature. Primary antibody mixes were applied to coverslips for one hour, followed by 3 washes with PBS-BT. Secondary antibodies (Goat anti-rabbit Alexa Fluor 568 and Goat anti-mouse Alexa Fluor 488, Life Technologies, Cat\# A11036 and A11029) were applied subsequently for one hour, followed by an additional 3 PBS-BT washes. Finally, nuclear staining was carried out by applying $100 \mathrm{ng} / \mathrm{mL}$ DAPI (Thermo Fisher Scientific, Cat\# D1306) for 15 min, followed by 5 washes with PBS-BT. Coverslips were mounted on microscope slides (Thermo Fisher Scientific, Cat\# 12-544-1) using Prolong Gold Antifade mounting media (Thermo Fisher Scientific, Cat\# P10144). Coverslips were imaged using a Lionheart FX Automated Microscope (BioTek, Winooski, VT), taking images using the GFP, Texas Red, and DAPI filter cubes at each imaged position. For each condition, 20 images were collected and all cells in each image were analyzed using CellProfiler 3.0.0 (McQuin et al., 2018) (Broad Institute, Cambridge, MA). A modified CellProfiler analysis pipeline was created based on the example "Fruit fly cells" pipeline available at https://cellprofiler.org/examples/, excluding all cells whose cytoplasm was not contained fully within the image field. Calculated per-cell mean fluorescence intensity values were extracted for the GFP and Texas Red channels from each image and plotted in Prism. 


\section{Chemical Library Screening}

To screen for small molecule modulators of Pim-induced death, $\mathrm{A} 54 \mathrm{~g}^{\mathrm{N}}$ cells were seeded in two parallel 384-well plates. A library of 261 bioactive compounds (Selleck Chemicals, Cat\# L2000) was diluted in SYTOX Green-containing DMEM from $2 \mathrm{mM}$ to $50 \mu \mathrm{M}$ in a dilution plate using a Versette liquid handler (Thermo Fisher Scientific). The day after seeding, the liquid handler was used to pipette SYTOX Green-containing media with either Pim or DMSO vehicle control into the assay plates containing $A 549^{\mathrm{N}}$ cells. The compound library from the dilution plate was subsequently added to each assay plate, diluting the library $10 \mathrm{X}$. The resulting assay plates contained $A 549^{\mathrm{N}}$ cells treated with either $5 \mu \mathrm{M}$ Pim or DMSO, plus the library compounds at a $5 \mu \mathrm{M}$ dose. The plates were subsequently analyzed by STACK, imaging on an IncuCyte (Essen BioScience) every $4 \mathrm{~h}$ for $120 \mathrm{~h}$ total and processed and analyzed as described above. Three independent replicates of the library screen were conducted, with subsequent analysis performed using the mean of the lethal fraction (LF) for the three replicates at each timepoint.

Compound interactions were scored as follows. Normalized area under the curve (nAUC) metrics were calculated and compared using a Bliss model of drug independence. nAUC was calculated by generating an AUC value from the LF curve and dividing this value by the maximum possible AUC: an LF value of 1 at every timepoint measured. A mean nAUC value for Pim was calculated from DMSO control wells in the Pim-treated plates from all three replicates. Using the nAUC values for Pim (P) and each library compound (L) in the DMSO-treated plate, an expected nAUC (E) was calculated for each combination of Pim plus the 
library compound based on the Bliss model: $E=P+L-(P * L)$. The deviation of the observed nAUC from this expected nAUC represented the enhancement or protection of Pim-induced death by the library compound.

\section{Quantification and Statistical Analysis}

Lethal fraction scoring was performed using Microsoft Excel 14.6.0 (Microsoft Corporation, Redmond, WA). LED curve fitting was performed using Prism 8 (GraphPad Software, La Jolla, CA). Flow cytometry data were analyzed using FlowJo 10.6.1 (FlowJo LLC, Ashland, OR). Immunofluorescence images were quantified using CellProfiler 3.0.0 (Broad Institute, Cambridge, MA). Graphing and statistical analyses were performed using Prism 8. Figures were assembled using Adobe Illustrator (Adobe Systems, San Jose, CA). Statistical details of experiments and statistical tests used can be found in the main text, figure legends, and STAR Methods.

\section{Data and Code Availability}

RNA-seq data are available in GEO under accession number GSE140172. 
bioRxiv preprint doi: https://doi.org/10.1101/2020.02.28.970079; this version posted February 29, 2020. The copyright holder for this preprint (which was not certified by peer review) is the author/funder, who has granted bioRxiv a license to display the preprint in perpetuity. It is made

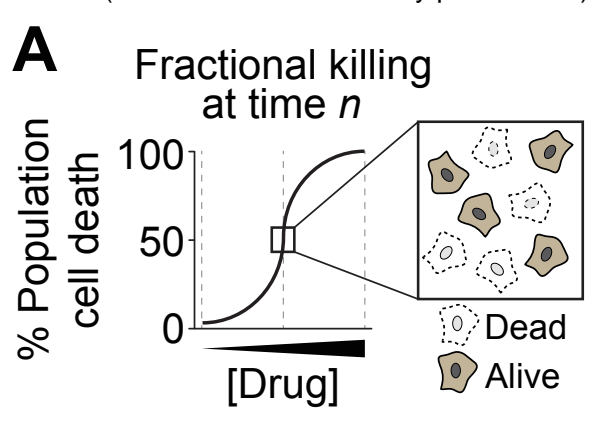
available under aCC-BY-NC-ND 4.0 International license.
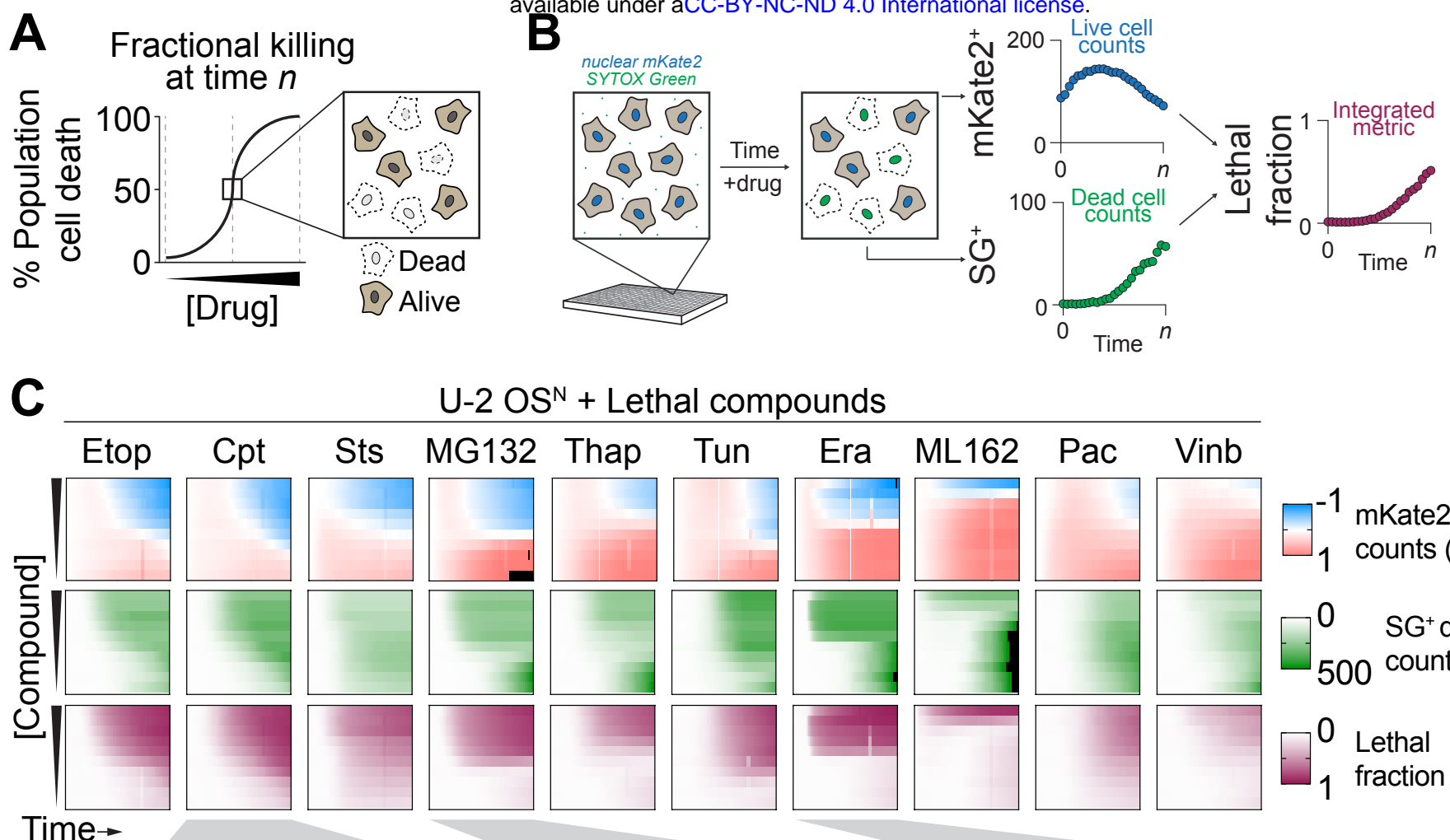

U-2 OSN + Lethal compounds
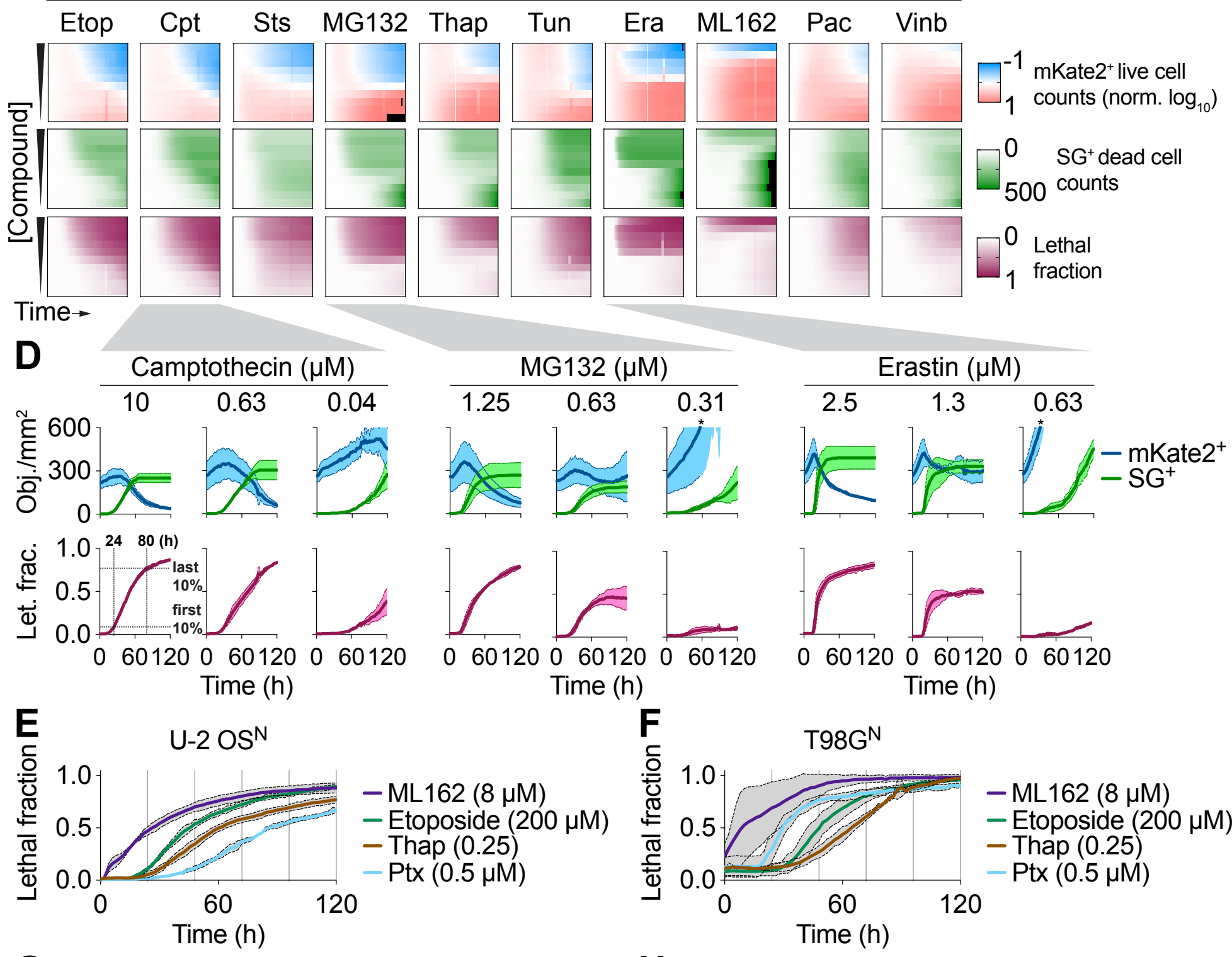

\section{G}

\section{Compound}

ML162

Etoposide

Thapsigargin

Paclitaxel
Lethal fraction at time:

\begin{tabular}{|c|c|c|c|c|}
\hline \multicolumn{5}{|c|}{ Time (h) } \\
\hline \multicolumn{5}{|c|}{ Lethal fraction at time: } \\
\hline $24 \mathrm{~h}$ & $48 \mathrm{~h}$ & $72 \mathrm{~h}$ & $96 \mathrm{~h}$ & $120 \mathrm{~h}$ \\
\hline 0.47 & 0.7 & 0.8 & 0.86 & 0.88 \\
\hline 0.11 & 0.54 & 0.72 & 0.83 & 0.9 \\
\hline 0.06 & 0.35 & 0.58 & 0.69 & 0.77 \\
\hline 0.02 & 0.12 & 0.37 & 0.56 & 0.67 \\
\hline
\end{tabular}

$-\mathrm{ML} 162(8 \mu \mathrm{M})$

- Etoposide $(200 \mu \mathrm{M})$

-Thap $(0.25)$

- Ptx $(0.5 \mu \mathrm{M})$
H

Compound

ML162

Etoposide

Thapsigargin

Paclitaxel

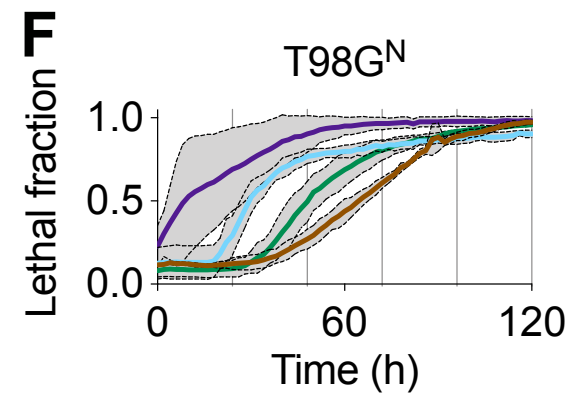

Lethal fraction at time:

$24 \mathrm{~h} \quad 48 \mathrm{~h} \quad 72 \mathrm{~h} \quad 96 \mathrm{~h} \quad 120 \mathrm{~h}$

$\begin{array}{lllll}0.69 & 0.9 & 0.97 & 0.98 & 0.98\end{array}$

$\begin{array}{lllll}0.09 & 0.5 & 0.81 & 0.92 & 0.96\end{array}$

$\begin{array}{lllll}0.12 & 0.27 & 0.61 & 0.89 & 0.97\end{array}$

$\begin{array}{lllll}0.29 & 0.77 & 0.83 & 0.87 & 0.93\end{array}$

Figure 1 
bioRxiv preprint doi: https://doi.org/10.1101/2020.02.28.970079; this version posted February 29, 2020. The copyright holder for this preprint (which was not certified by peer review) is the author/funder, who has granted bioRxiv a license to display the preprint in perpetuity. It is made

A Analysis of cell
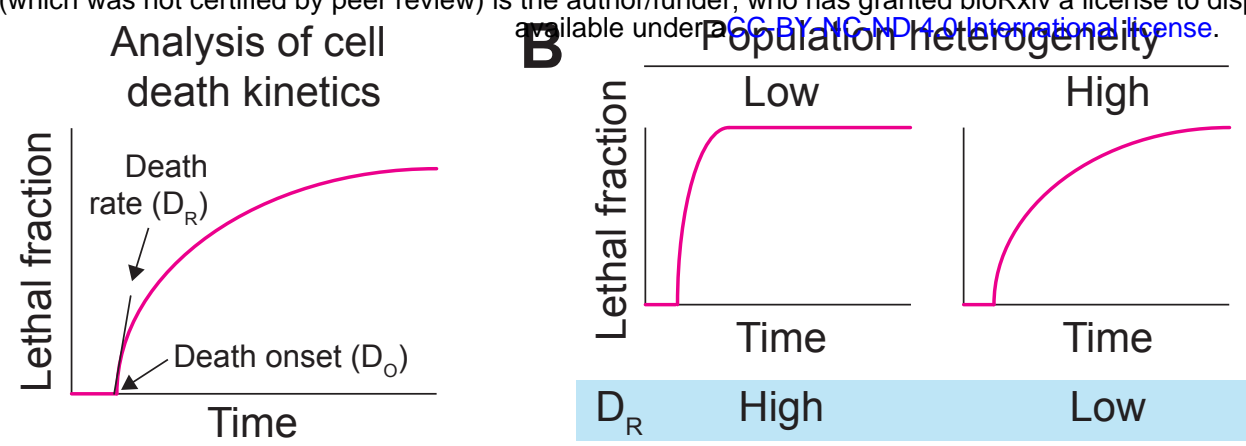

C

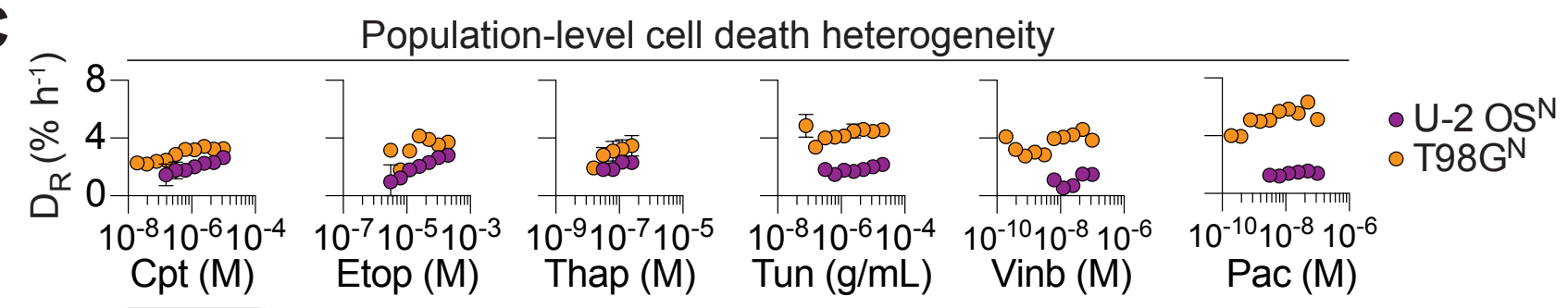

D

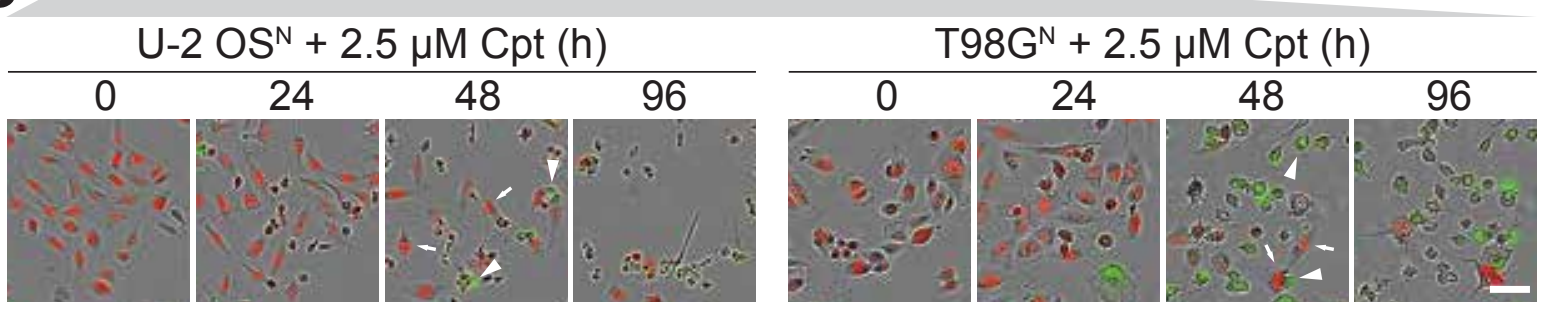

Live $\left(\right.$ mKate2 ${ }^{+}$) / Dead (SYTOX Green $\left.{ }^{+}\right)$
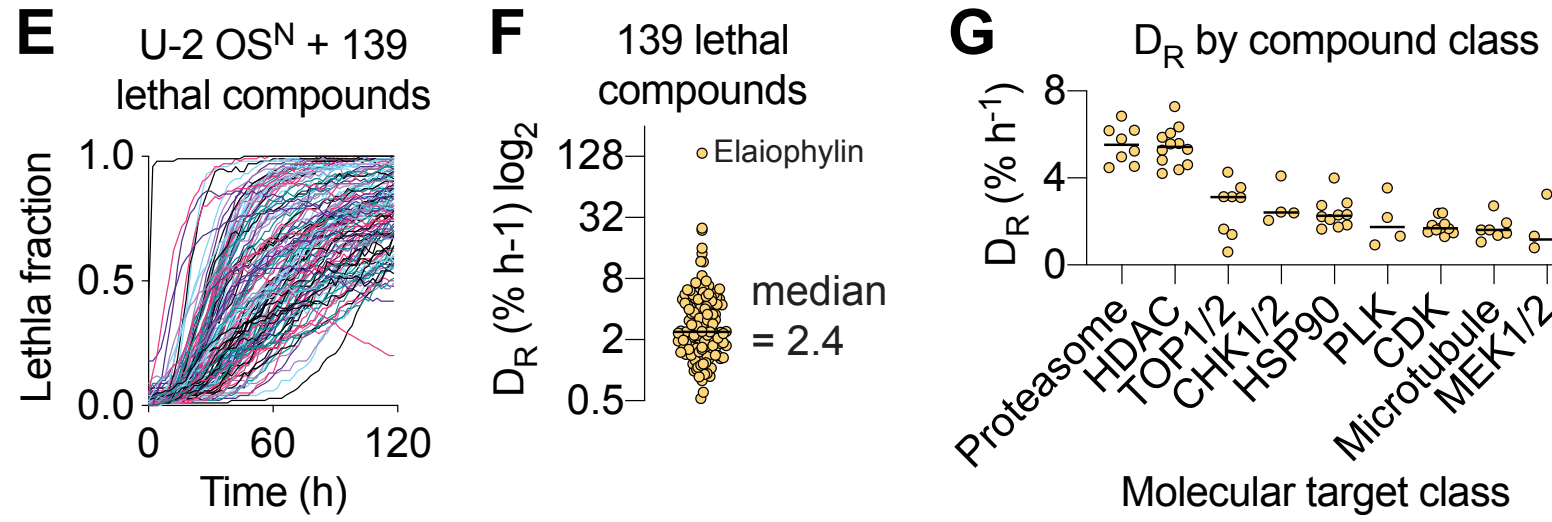

H

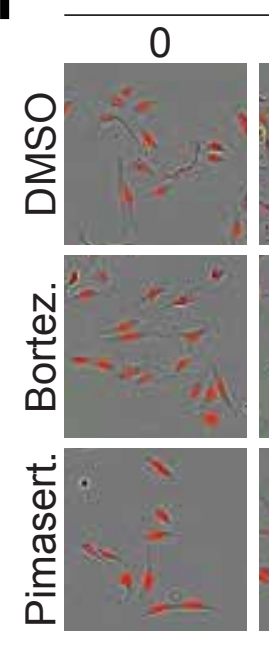

$\mathrm{U}-2 \mathrm{OS}^{\mathrm{N}}$ cells over time $(\mathrm{h})$
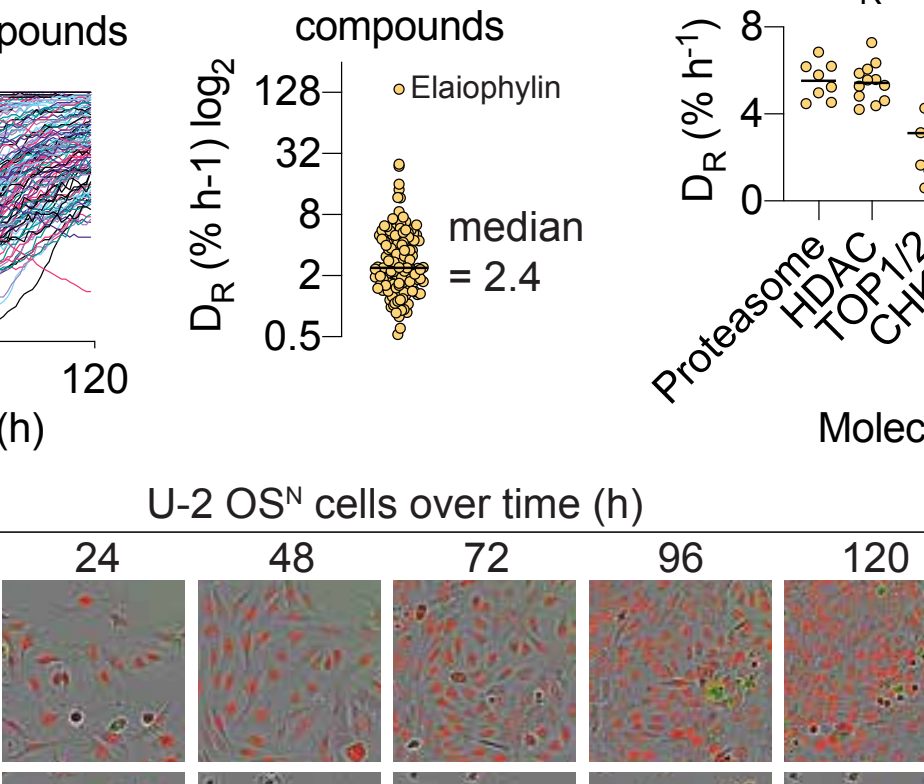

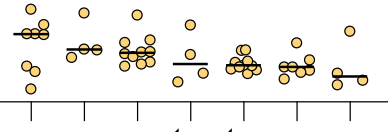

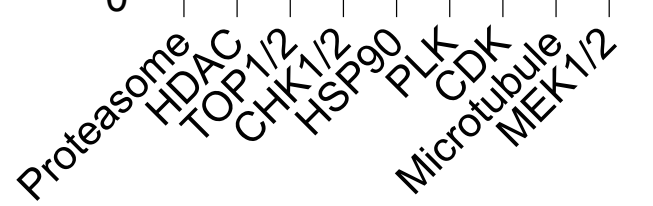

Molecular target class
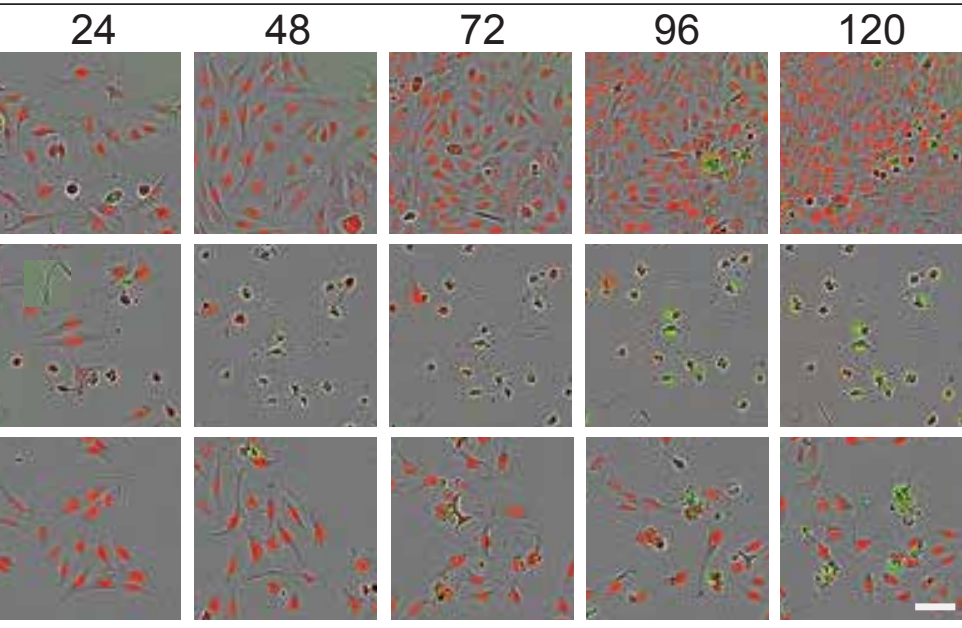

$D_{R} \% h^{-1}(95 \%$ C.I. $)$

n.d.

Live (mKate2 ${ }^{+}$) / Dead (SYTOX Green ${ }^{+}$)

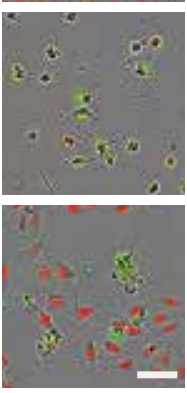

$5.8(5.4-6.2)$

$2.0(1.7-2.7)$

Figure 2 
bioRxiv preprint doi: https://doi.org/10.1101/2020.02.28.970079; this version posted February 29, 2020. The copyright holder for this preprint (which was not certified by peer review) is the author/funder, who has granted bioRxiv a license to display the preprint in perpetuity. It is made available under aCC-BY-NC-ND 4.0 International license.
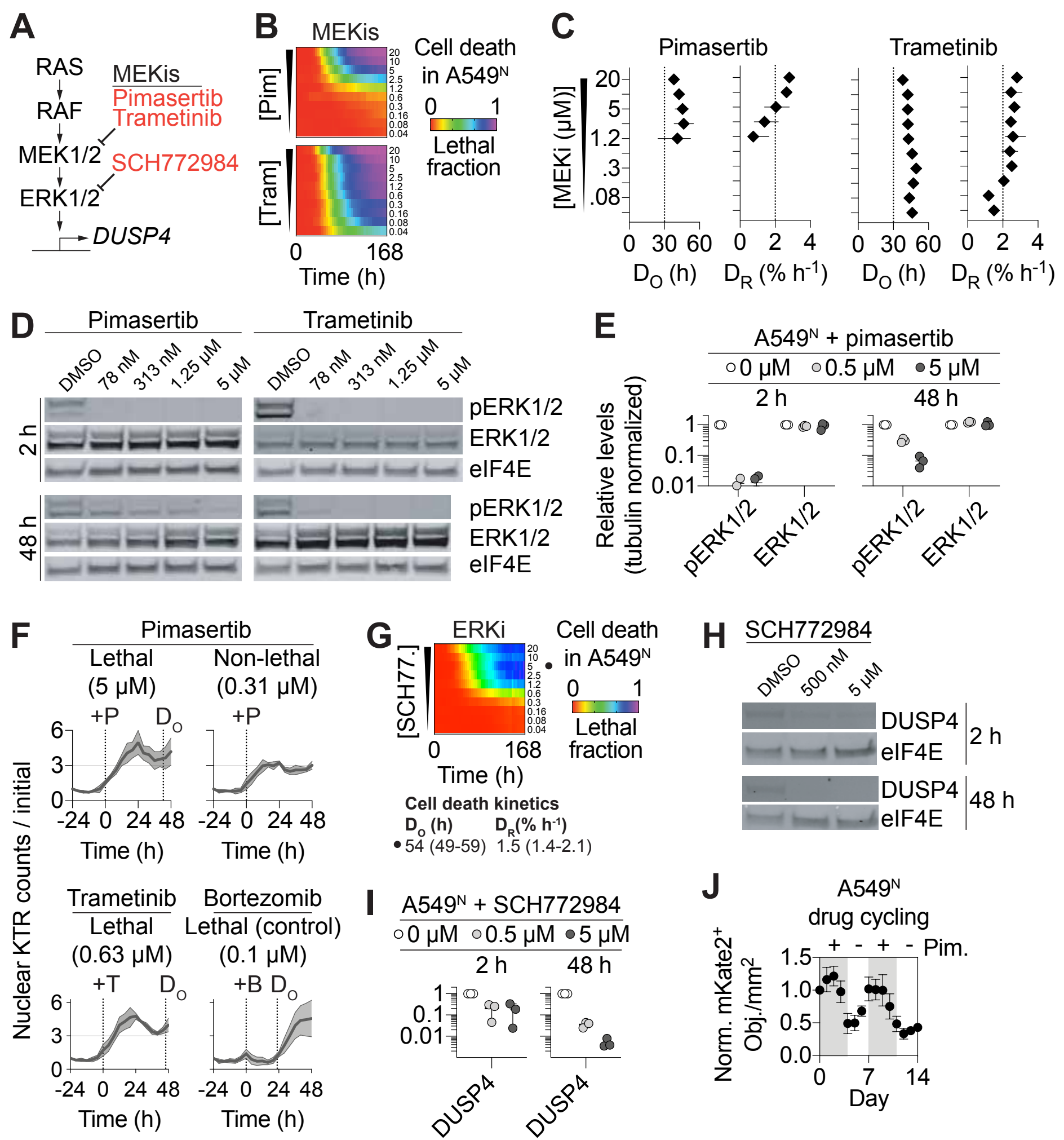

$$
\begin{aligned}
& \text { Cell death kinetics } \\
& \begin{array}{cl}
\mathbf{D}_{\mathrm{O}}(\mathbf{h}) & \mathbf{D}_{\mathrm{R}}\left(\% \mathbf{~ h}^{-1}\right) \\
\text { - } 54(49-59) & 1.5(1.4-2.1)
\end{array}
\end{aligned}
$$

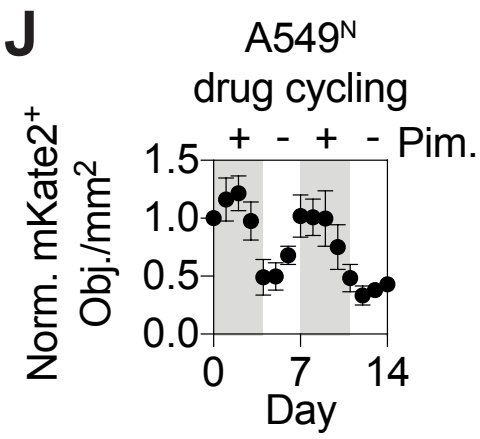

Figure 3 
bioRxiv preprint doi: https://doi.org/10.1101/2020.02.28.970079; this version posted February 29, 2020. The copyright holder for this preprint (which was not certified by peer review) is the author/funder, who has granted bioRxiv a license to display the preprint in perpetuity. It is made available under aCC-BY-NC-ND 4.0 International license.

A RNA seq upregulated genes versus DMSO, Adj $P<0.05$ )

$0.5 \mu \mathrm{M}$ $5 \mu \mathrm{M}$

A549 371 2275

Calu-6 ${ }^{\mathrm{N}}$

C

A-1155463

D

ABT-737 $\mathbf{S 6 3 8 4 5}$

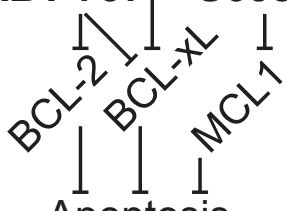

Apoptosis

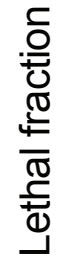

B

\begin{tabular}{l}
\hline GO term \\
0050793 \\
0007010 \\
0045595 \\
0048523 \\
0010942 \\
0043068 \\
2000026 \\
0043065 \\
0051094
\end{tabular}

$\mathrm{A} 549^{\mathrm{N}}$

Pim Tram

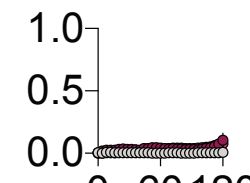

DMSO

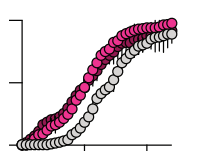
$(0.5 \mu \mathrm{M})$

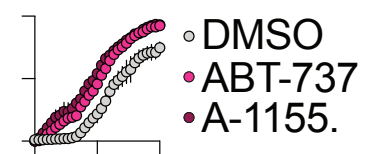

Description

regulation of developmental process

cytoskeleton organization

regulation of cell differentiation

negative regulation of cellular process

positive regulation of cell death

positive regulation of programm

regulation of multicell. organismal dev. 1.04E-03

positive regulation of developmental process $1.89 \mathrm{E}-03$

1.30E-04

8.75E-04

1.61E-03

1.24E-03

1.04E-03 positive regulation of apoptotic process 1.65E-03

FDR q value

060120060120060120

Time (h)

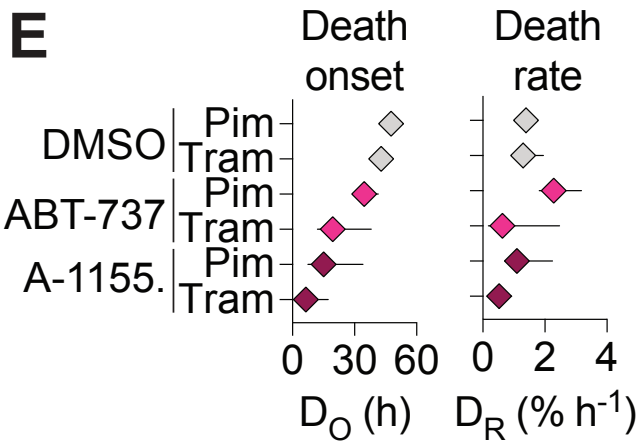

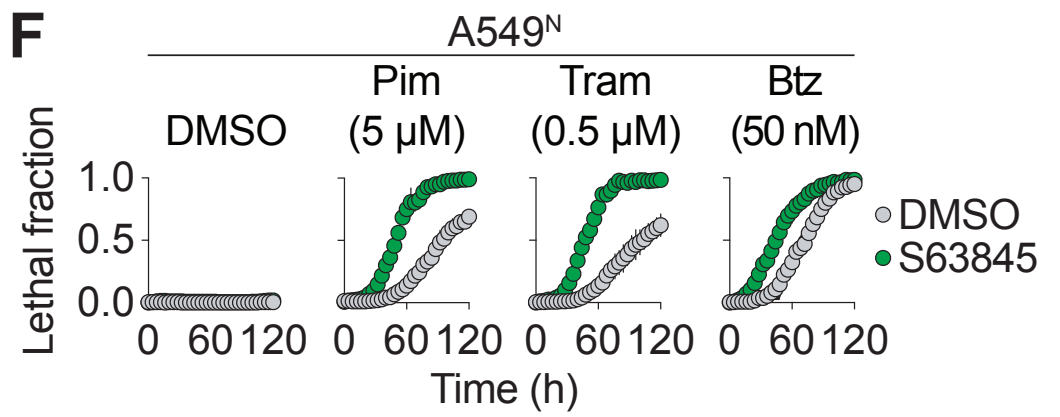

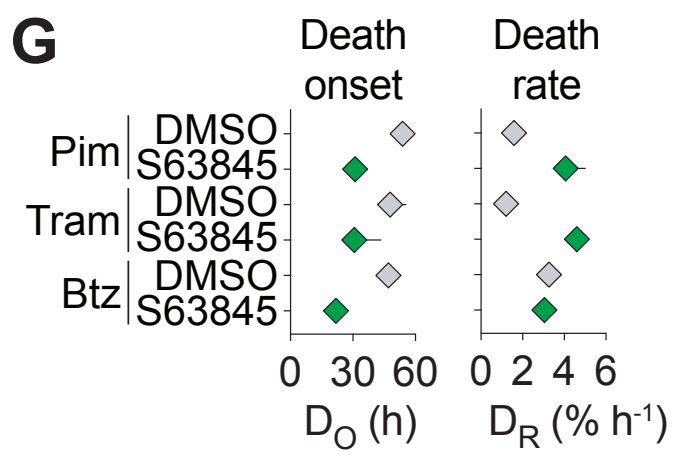

H

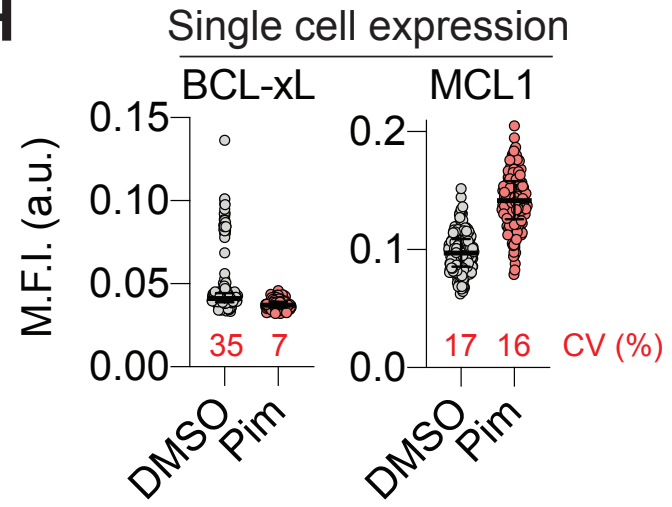

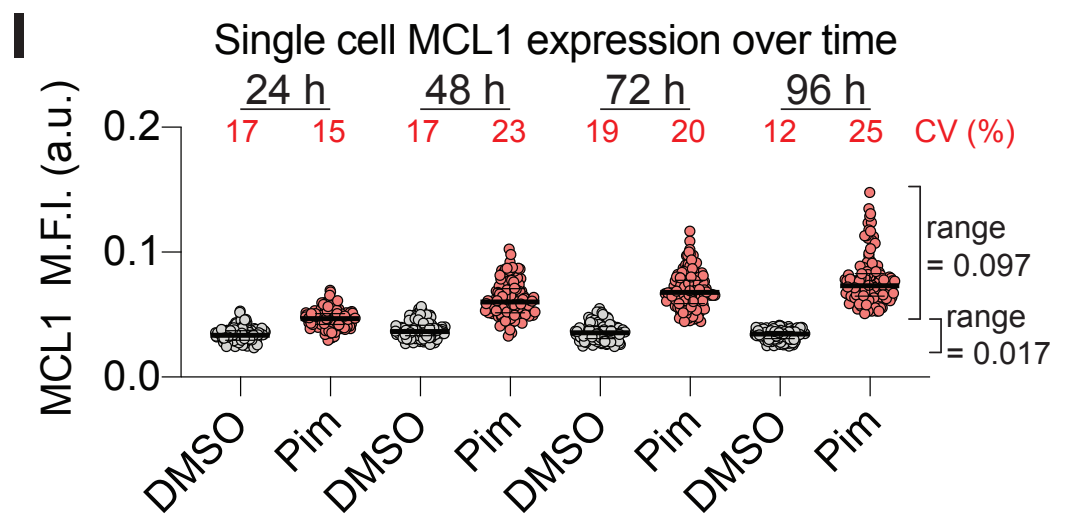

Single cell MCL1 expression over time
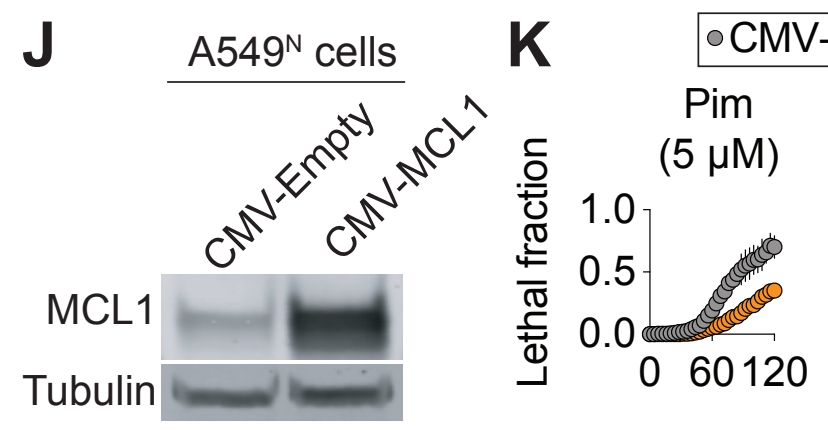

Tram

$(0.5 \mu \mathrm{M})$

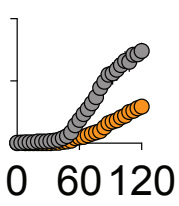

Time (h)

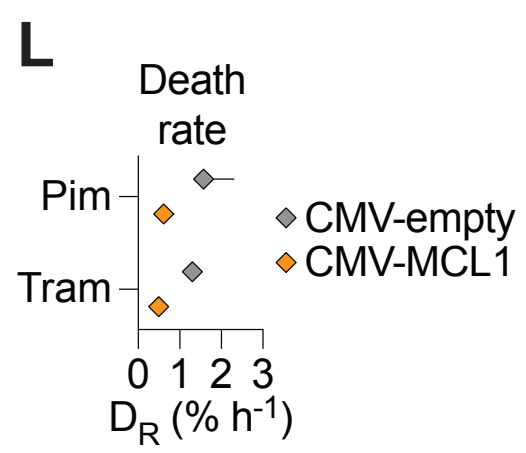


A single cell cloning

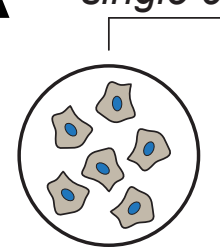

A549 population

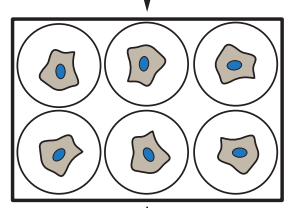

Expansion and compound treatment
Clone 1 Clone 2 Clone $n$

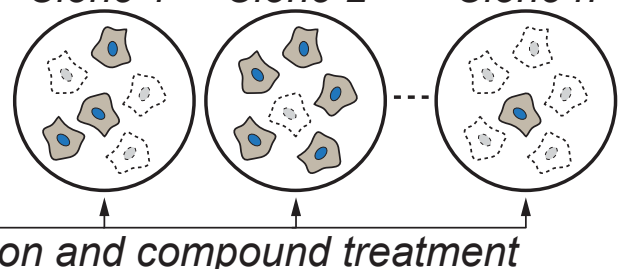

B

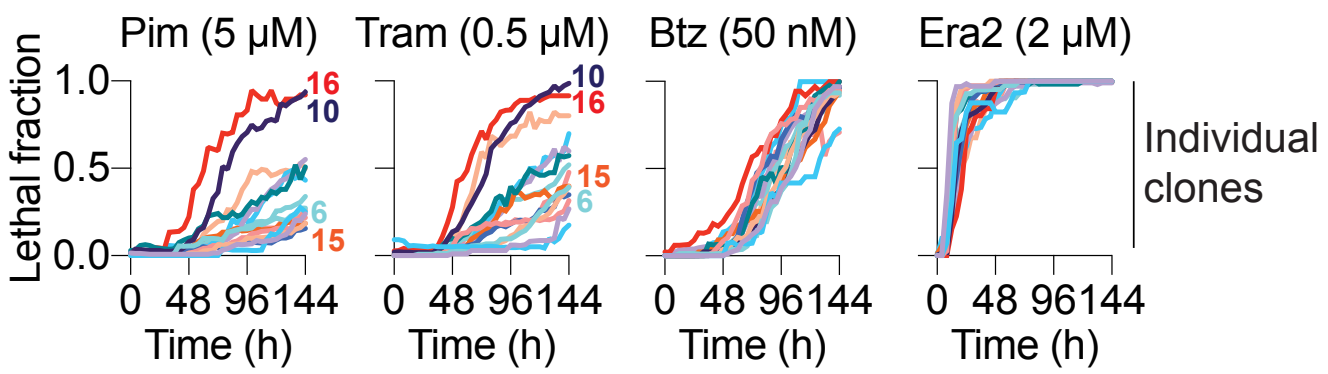

C

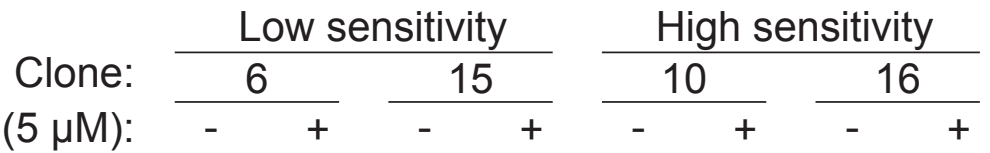

pERK $1 / 2$

$\mathrm{BCL}-\mathrm{xL}$

$\mathrm{BIM}$

MCL1

D

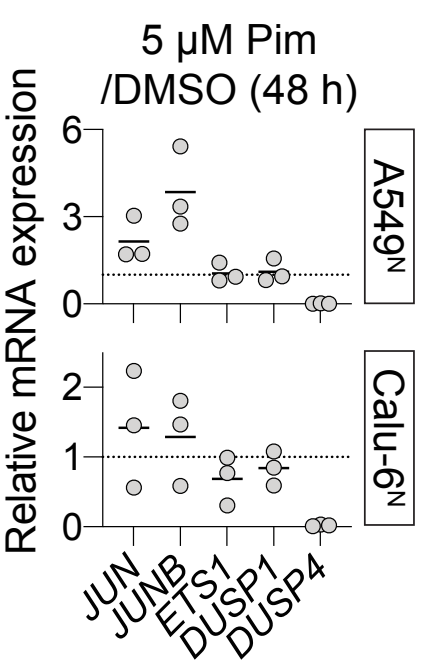

E

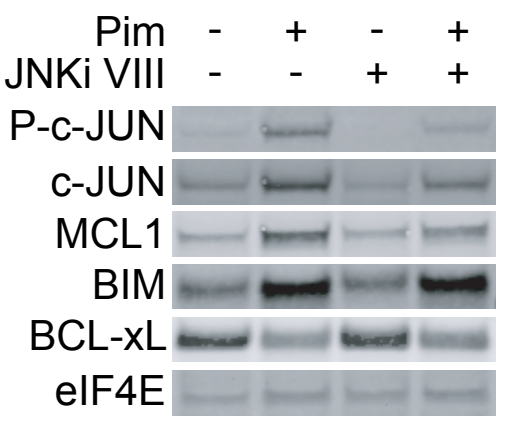

Figure 5 
bioRxiv preprint doi: https://doi.org/10.1101/2020.02.28.970079; this version posted February 29, 2020. The copyright holder for this preprint (which was not certified by peer review) is the author/funder, who has granted bioRxiv a license to display the preprint in perpetuity. It is made available under aCC-BY-NC-ND 4.0 International license.

A Pimasertib-compound interaction analysis

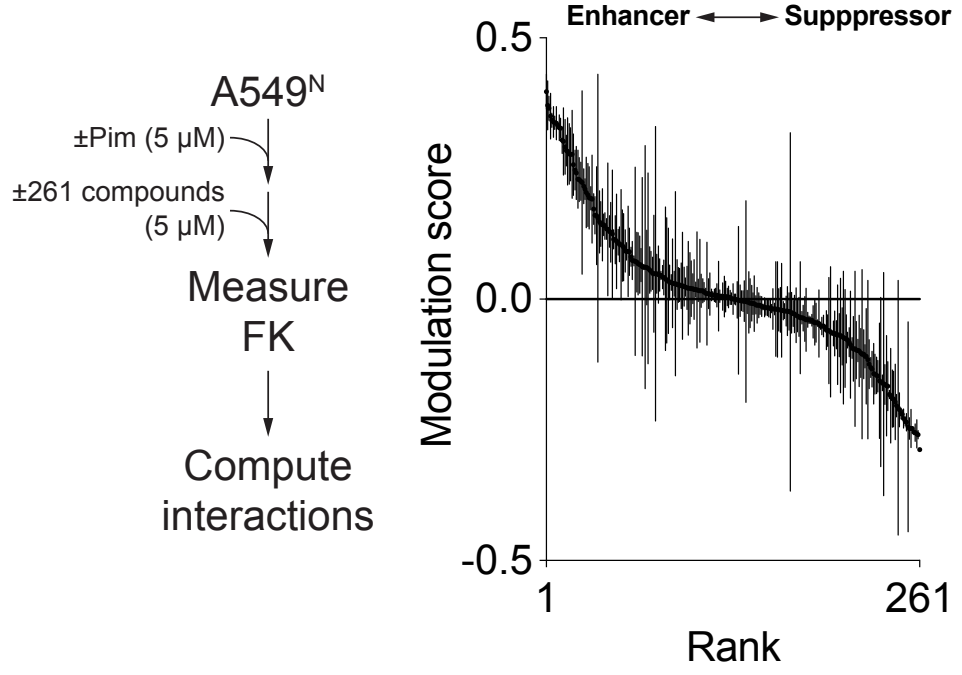

B

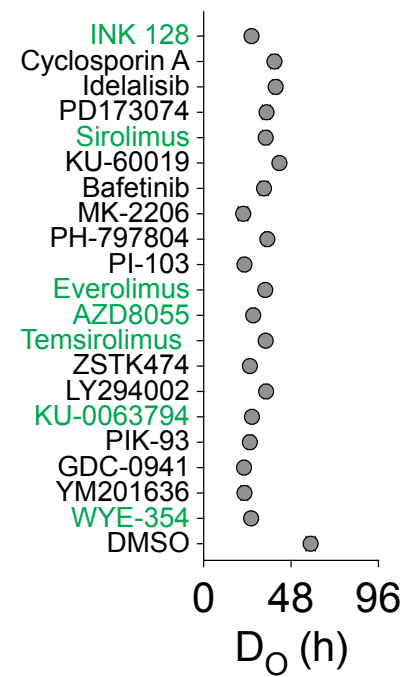

Top 20 enhancers of FK

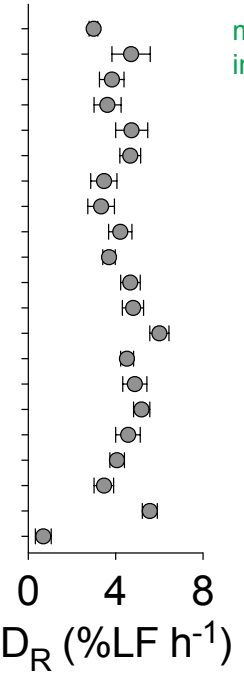

C

A549N

0 DMSO $\circ$ Rapamycin $\circ$ AZD8055
Pim Tram $\quad$ Btz

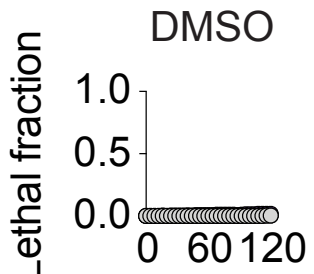

$(5 \mu \mathrm{M})$

$(0.5 \mu \mathrm{M}) \quad(0.5 \mu \mathrm{M})$
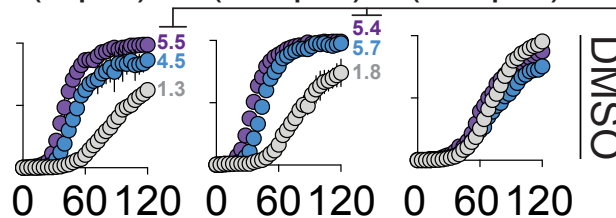

\section{Time (h)}

$\mathbf{E}$

A549

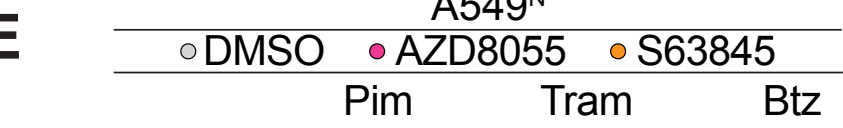

DMSO

$(5 \mu \mathrm{M})$

(500 nM)

$(50 \mathrm{nM})$ $\mathrm{O}_{\mathrm{a}}(\mathrm{sh}) \mathrm{R}$
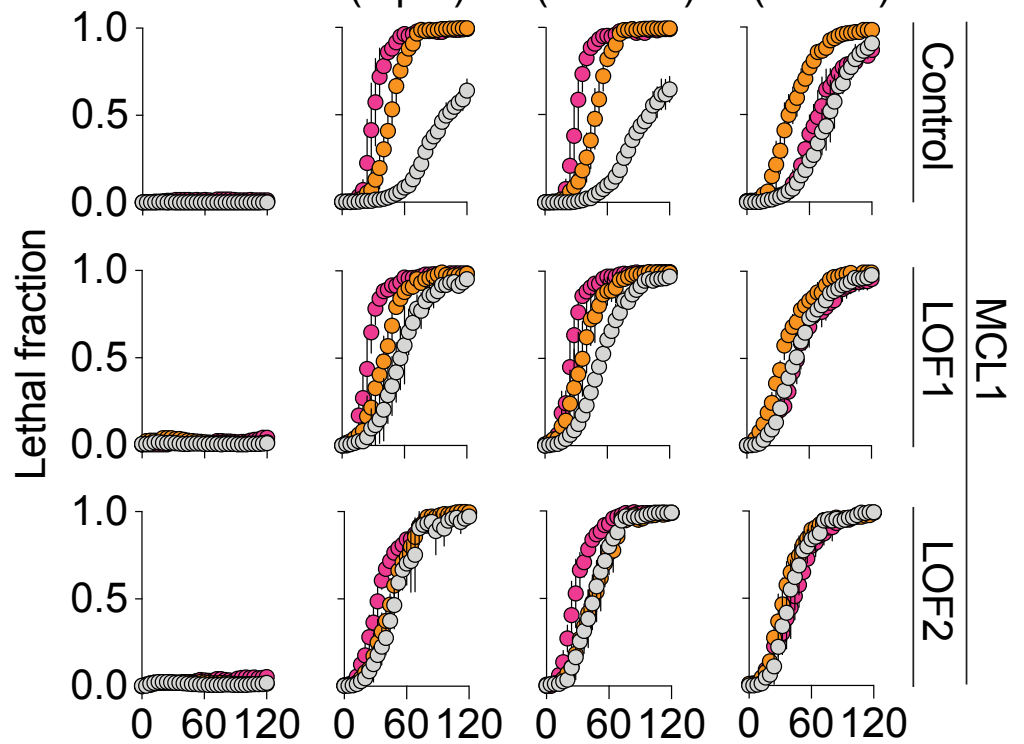

Time (h)

D

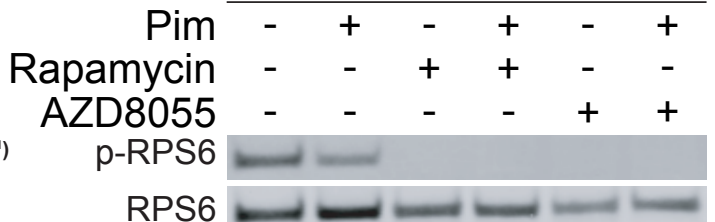

p-4EBP1

4EBP1

MCL1

BIM

$B C L-x L$

elF4E

F

A549
mTOR inhibitors nitors 
bioRxiv preprint doi: https://doi.org/10.1101/2020.02.28.970079; this version posted February 29, 2020. The copyright holder for this preprint (which was not certified by peer review) is the author/funder, who has granted bioRxiv a license to display the preprint in perpetuity. It is made available under aCC-BY-NC-ND 4.0 International license.
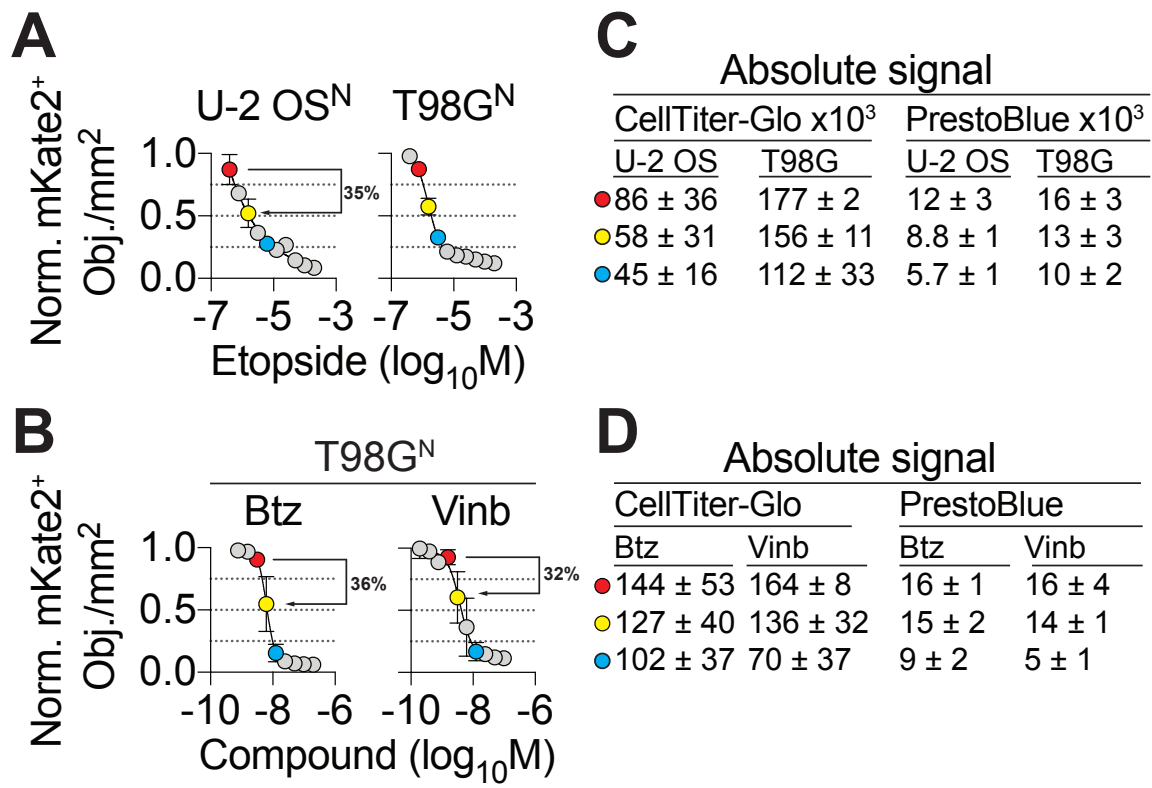

$\mathbf{E}$

Absolute signal

CellTiter-Glo $\times 10^{3}$ PrestoBlue $\times 10^{3}$

$\frac{\overline{U-2 O S}}{\frac{\mathrm{T} 98 \mathrm{G}}{176 \pm 2}} \frac{\overline{U-2 O S}}{12 \pm 3} \frac{\mathrm{T} 98 \mathrm{G}}{16 \pm 3}$

$058 \pm 31 \quad 156 \pm 11 \quad 8.8 \pm 1 \quad 13 \pm 3$

$045 \pm 16 \quad 112 \pm 33 \quad 5.7 \pm 1 \quad 10 \pm 2$

\begin{tabular}{|c|c|c|c|}
\hline \multicolumn{4}{|c|}{ Signal / cell } \\
\hline \multicolumn{2}{|c|}{ CellTiter-Glo } & \multicolumn{2}{|c|}{ PrestoBlue } \\
\hline $\mathrm{U}-2 \mathrm{O}$ & T98C & U-2 OS & T98G \\
\hline 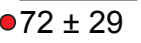 & 24 & & \\
\hline & 325 & & \\
\hline $0117 \pm$ & $430 \pm$ & $15 \pm 3$ & $39 \pm$ \\
\hline
\end{tabular}

$\mathbf{F}$

\begin{tabular}{|c|c|c|c|}
\hline \multicolumn{2}{|c|}{ CellTiter-Glo } & \multicolumn{2}{|c|}{ PrestoBlue } \\
\hline Btz & Vinb & Btz & Vinb \\
\hline 178 & $177 \pm 52$ & $20 \pm 1$ & $19 \pm 2$ \\
\hline $169 \pm$ & $173 \pm 43$ & $20 \pm 1$ & $19 \pm 6$ \\
\hline $225 \pm$ & $296 \pm 65$ & $21 \pm 4$ & $33 \pm 16$ \\
\hline
\end{tabular}

G

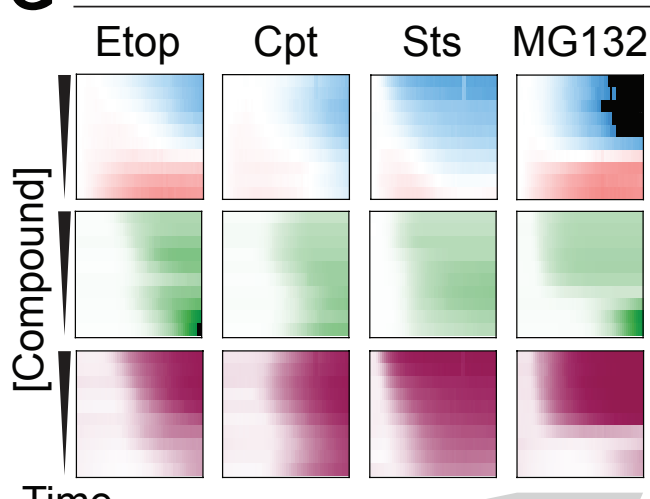

T98G + Lethal compounds
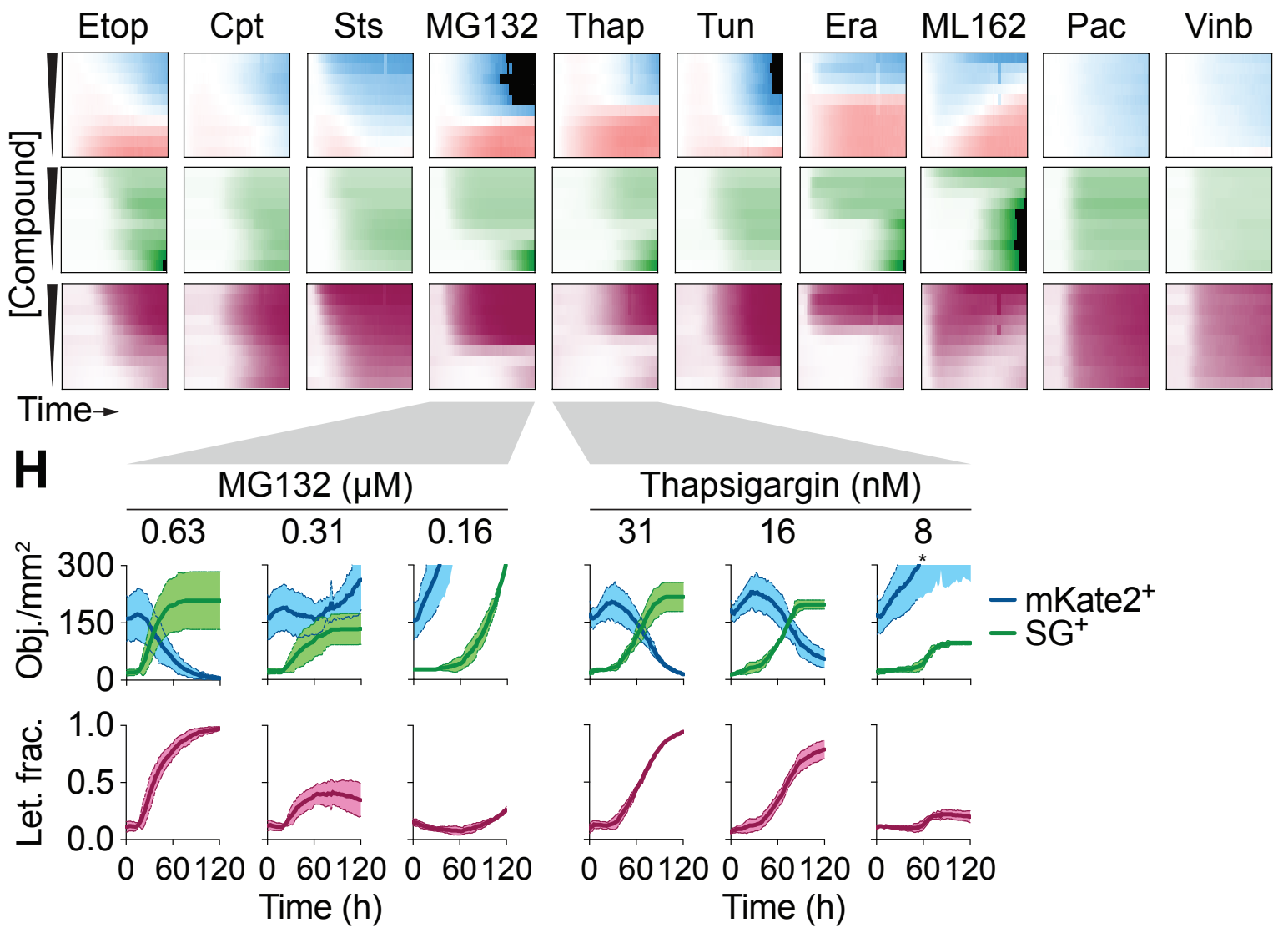

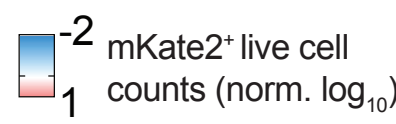
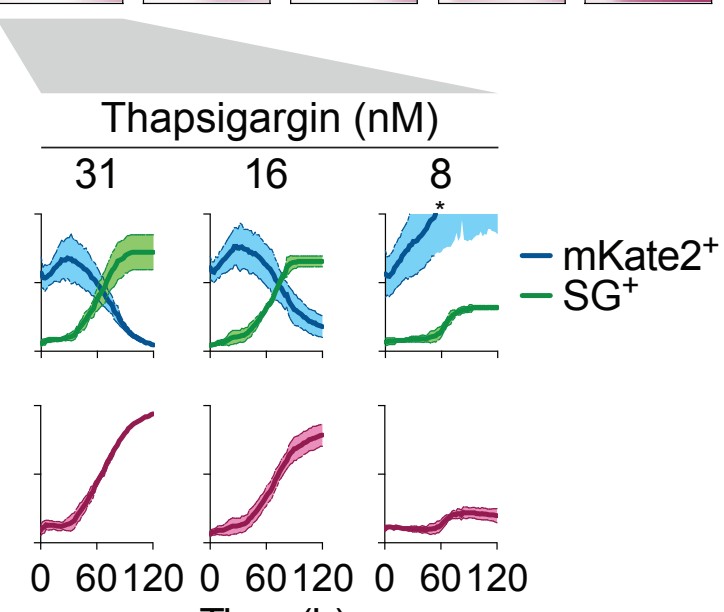

Time (h)

Supplemental Figure 1, related to Figure 1. High-throughput assessment of fractional killing between conditions. (A,B) Assessment of live cell counts (mKate2 positive [mKate $2^{+}$] objects) over lethal compound concentration-response series in two cell lines. Measurements were performed at $72 \mathrm{~h}$. Btz: bortezomib, Vinb: vinblastine. Percent reduction in live cell counts between different compound concentrations is indicated by black lines and arrows and discussed in the main text. (C,D). Absolute metabolic viability measurements at select dose points. Colored circles in $\mathrm{C}$ and $\mathrm{D}$ correspond to specific doses indicated on the curves in A and B, respectively. (E,F). Metabolic viability measurements normalized per cell. Colored circles in $\mathrm{E}$ and $\mathrm{F}$ correspond to specific doses indicated on the curves in $\mathrm{A}$ and $\mathrm{B}$, respectively. (G) Heatmap summaries of normalized, $\log _{10}$-scaled live mKate2 positive (mKate2+) live cell counts, SYTOX Green positive (SG+) dead cell counts, and integrated lethal fraction (Let. Frac.) scores over time (x-axis) and concentration (y-axis) for ten compounds in T98 $\mathrm{G}^{\mathrm{N}}$ cells. For the $\mathrm{mKate} 2^{+}$heatmaps, live cell counts were normalized to 1 at time $=0$ and expressed on a $\log _{10}$ scale. Values more than 10 -fold lower than the starting values are colored black. Etop: etoposide, Cpt: camptothecin, Sts: staurosporine, Thap: thapsigargin, Tun: tunicamycin, Era: erastin, Pac, paclitaxel. (H) Live and dead cell counts for T98 $\mathrm{G}^{\mathrm{N}}$ cells, extracted from the data shown in G. Data are from three independent experiments and represent mean $\pm \mathrm{SD}(\mathrm{A}-\mathrm{F}, \mathrm{H})$ or mean $(\mathrm{G})$. 
A
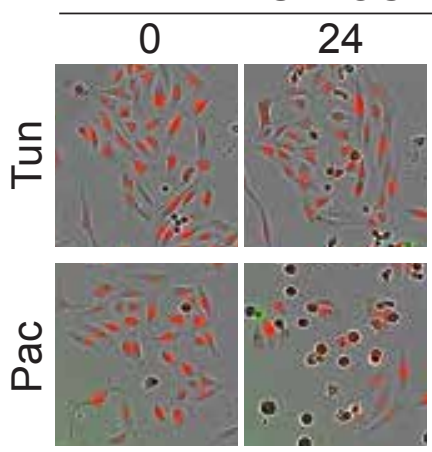

Live (mKate2 $\left.{ }^{+}\right) /$Dea

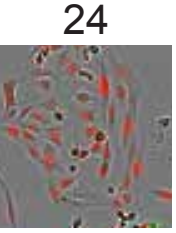

$\mathrm{U}-2 \mathrm{OS}^{\mathrm{N}}$ - time $(\mathrm{h})$
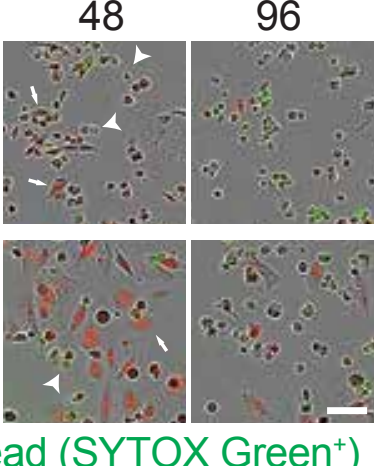

B

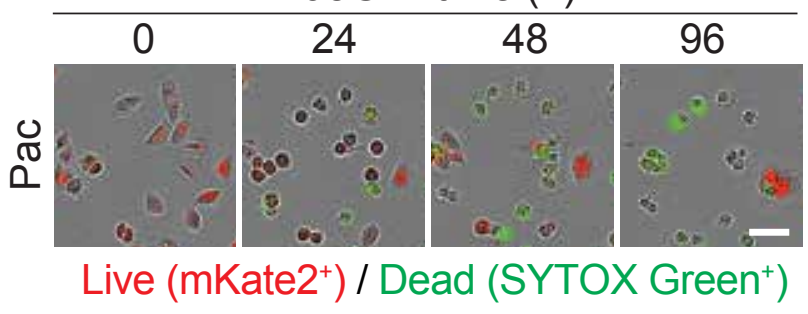

Supplemental Figure 2, related to Figure 2. Kinetic analysis of FK. (A,B) Representative images for U-2 OS ${ }^{\mathrm{N}}(\mathrm{A})$ and $\mathrm{T} 98 \mathrm{G}^{\mathrm{N}}$ (B) cells treated with the indicated lethal compounds over time. Arrows indicate example live cells, Arrowheads example dead cells. Images correspond to the underlying data analyzed as part of Figure 1. Scale bar $=75 \mu \mathrm{M}$. Tun: tunicamycin, Pac: paclitaxel. 
bioRxiv preprint doi: https://doi.org/10.1101/2020.02.28.970079; this version posted February 29, 2020. The copyright holder for this preprint (which was not certified by peer review) is the author/funder, who has granted bioRxiv a license to display the preprint in perpetuity. It is made
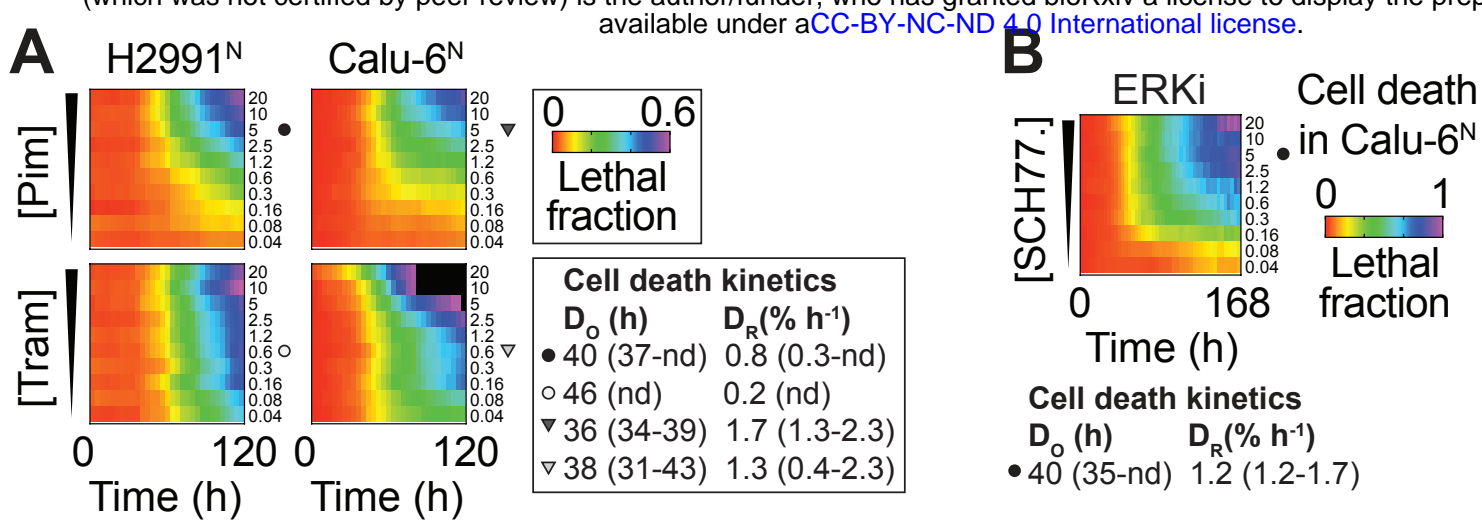

\section{Cell death kinetics}

$D_{0}(h) \quad D_{R}\left(\% h^{-1}\right)$

- 40 (35-nd) $1.2(1.2-1.7)$
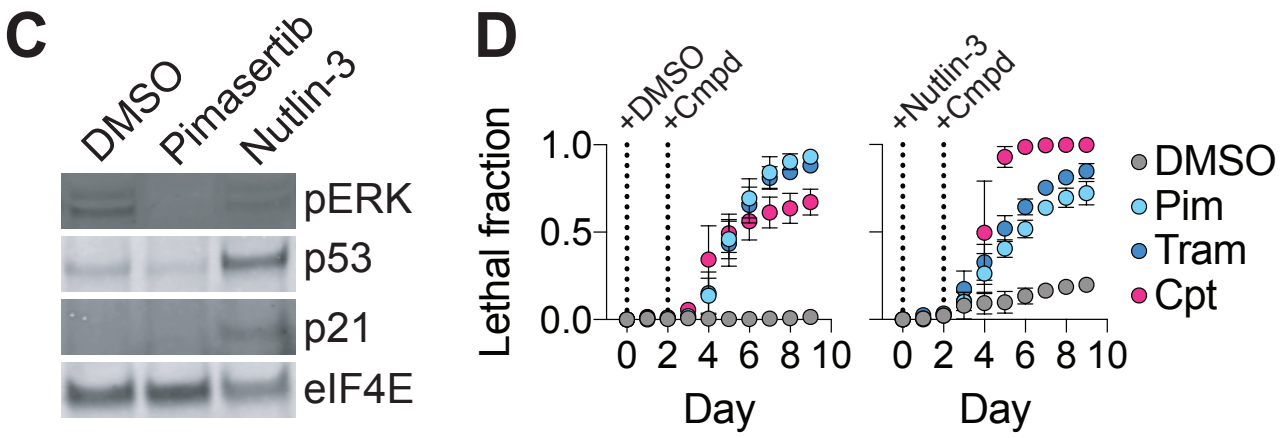

E Cell cycle phase

Day Day
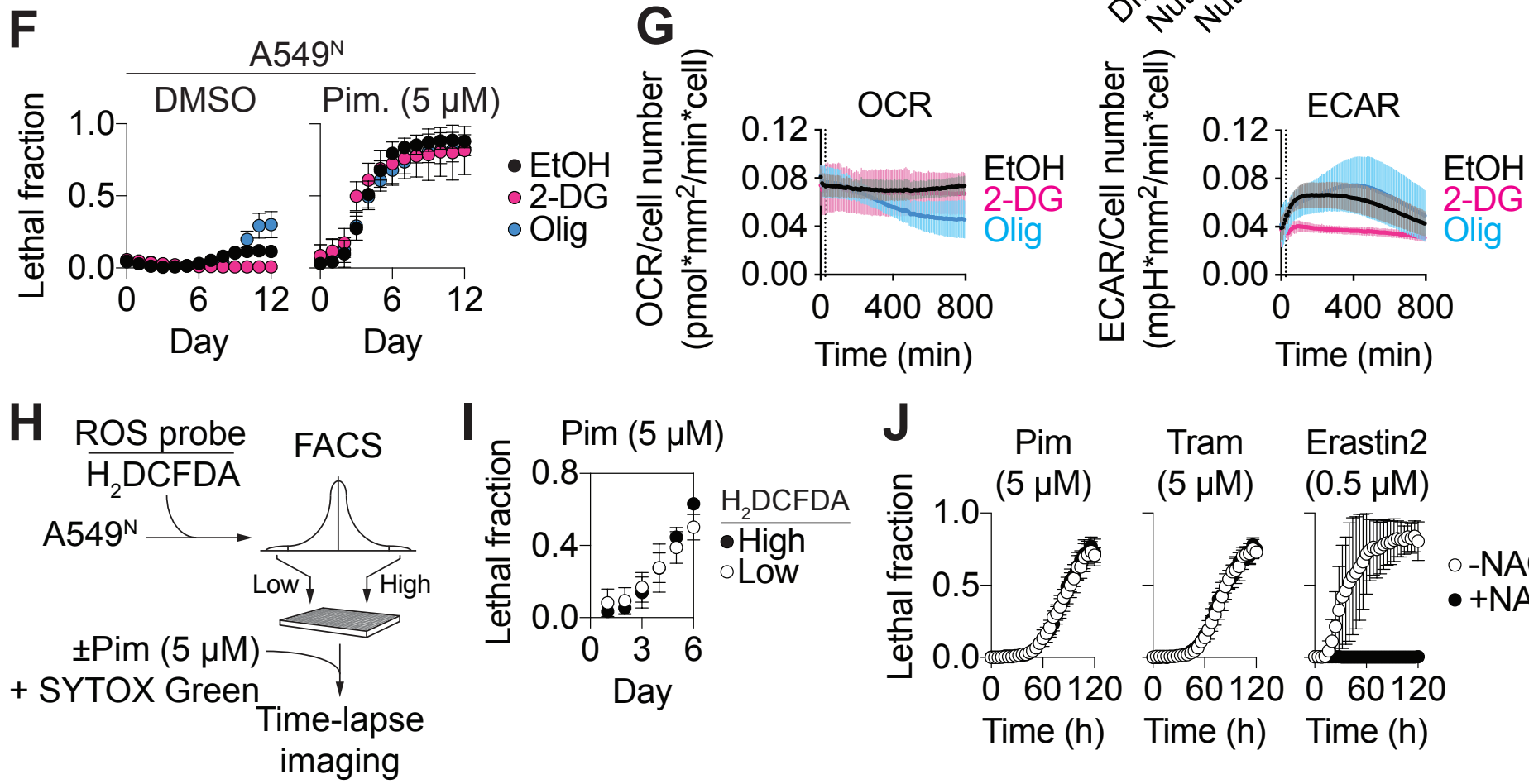

Figure S3, related to Figure 3. Investigating the MEKi-induced fractional killing. (A) Cell death summarized over time and MEKi concentration. Data are mean values from three independent experiments. Cell death kinetic parameters for select concentrations indicated by the symbols are shown at right, with 95\% confidence intervals in brackets. nd: not determined. (B) Cell death summarized over time and SCH772984 concentration. Data are mean values from three independent experiments. Cell death kinetic parameters for one concentration indicated by the black circle are shown, with 95\% confidence intervals in brackets. nd: not determined. (C) Phospho-ERK1/2 (pERK), p53 and p21 levels in A549N cells \pm nutlin-3 (10 $\mu \mathrm{M}, 48 \mathrm{~h})$. (D) Cell death over time following pretreatment (2 day) \pm nutlin-3 $(10 \mu \mathrm{M})$. + Cmpd indicates the time of pimasertib (Pim, $5 \mu \mathrm{M})$, trametinib (Tram, $5 \mu \mathrm{M})$ or camptothecin $(\mathrm{Cpt}, 10 \mu \mathrm{M})$ addition. p53 stabilization has no effect on the kinetics of MEKi-induced cell death. (E) Analysis of cell cycle phase by PI/FACS \pm nutlin-3 (10 $\mu \mathrm{M})$ for the indicated times. (F) Cell death \pm pimasertib \pm vehicle (ethanol, EtOH), 2-deoxyglucose (2-DG, $10 \mathrm{mM})$ or oligomycin (Olig, 100 nM). Disruption of bioenergetics has no effect on FK. (G) Oxygen consumption (OCR) and extracellular acidification (ECAR) determined using a Seahorse assay in A549 ${ }^{\mathrm{N}}$ cells \pm 2 -DG or Olig as in F. (H) Outline of FACS-based scheme to isolate cells with high or low intracellular ROS as assessed using $\mathrm{H}_{2}$ DCFDA. (I) Cell death over time for isolated $\mathrm{H}_{2}$ DCFDA $^{\text {High }}$ and $\mathrm{H}_{2} \mathrm{DCFDA}^{\text {Low }}$ sub-populations exposed to pimasertib $(5 \mu \mathrm{M})$. $(\mathrm{J})$ Cell death over time in $\mathrm{A} 549^{\mathrm{N}}$ cells \pm MEKis $\pm \mathrm{N}$-acetylcysteine (NAC, $\left.1 \mathrm{mM}\right)$. Erastin2 is a positive control compound that induces oxidative cell death. Data in D-G, I and J are mean \pm SD from at least three independent experiments. 
bioRxiv preprint doi: https://doi.org/10.1101/2020.02.28.970079; this version posted February 29, 2020. The copyright holder for this preprint (which was not certified by peer review) is the author/funder, who has granted bioRxiv a license to display the preprint in perpetuity. It is made

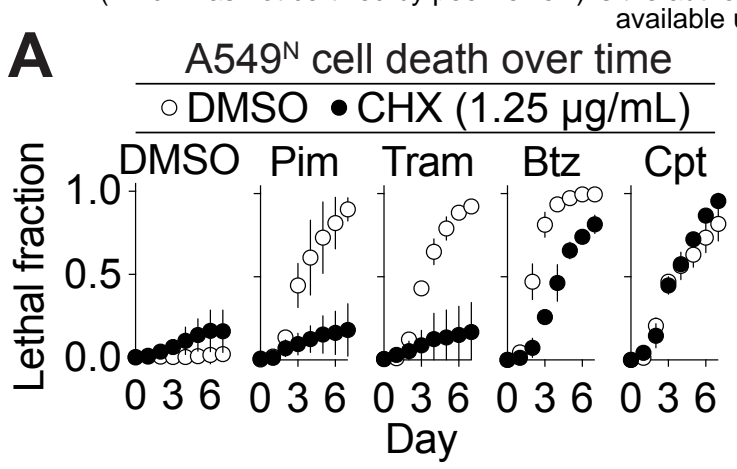
available under aCC-BY-NC-ND 4.0 International license.

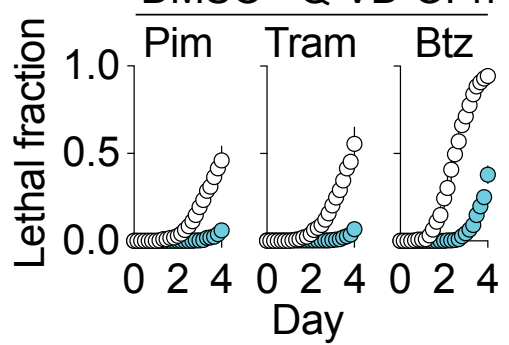

D
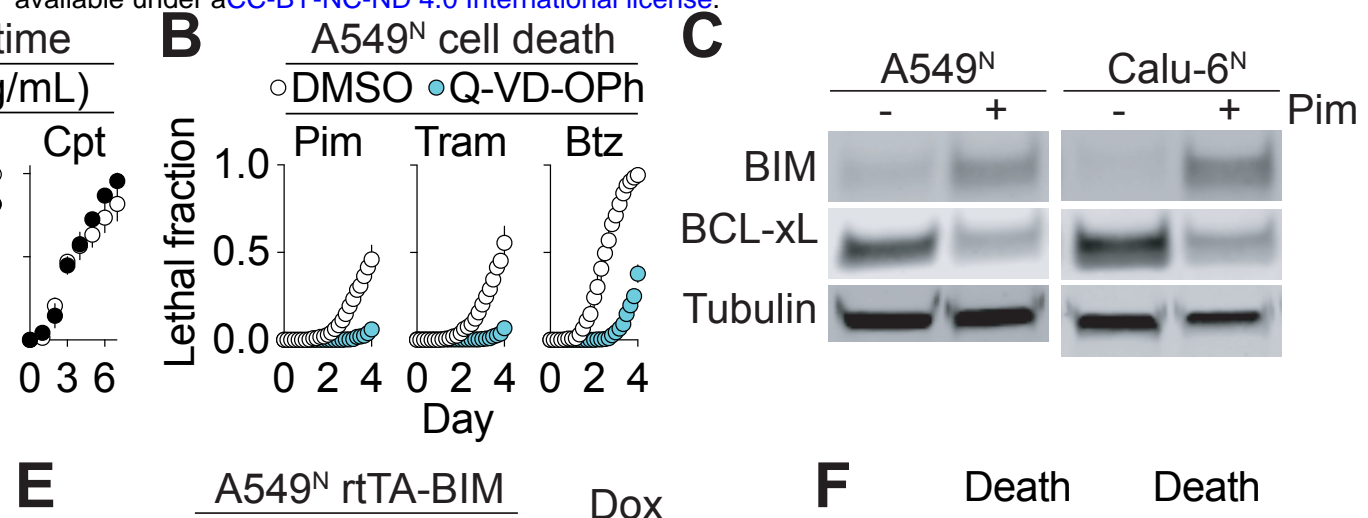

BIM

$B C L-x L$

Tubulin
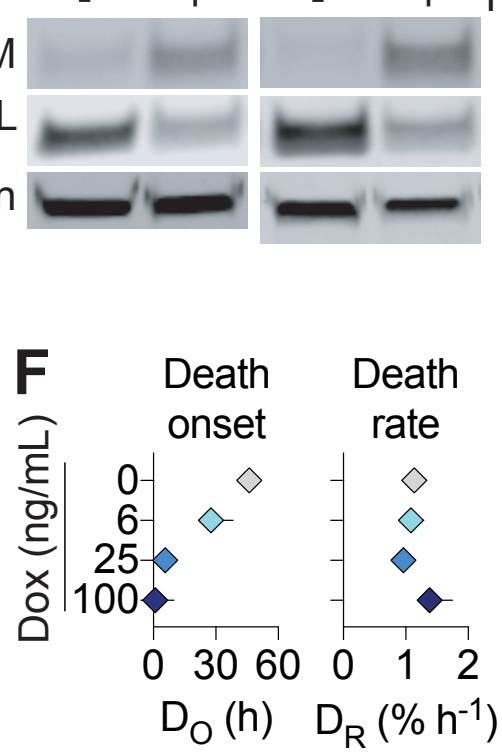

$\mathbf{G}$

A549 rtTA-BIM $^{\mathrm{G} 156 \mathrm{E}}$

$\begin{array}{llll}0 & 6 & 25100 \text { Dox }(\mathrm{ng} / \mathrm{mL})\end{array}$

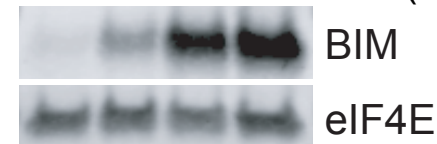

E

H

Time (h)

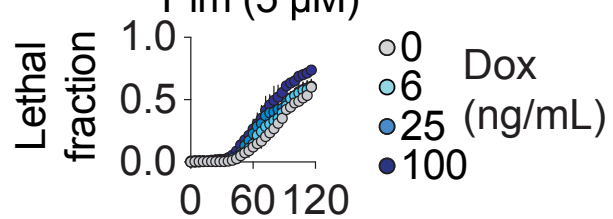

Time (h)
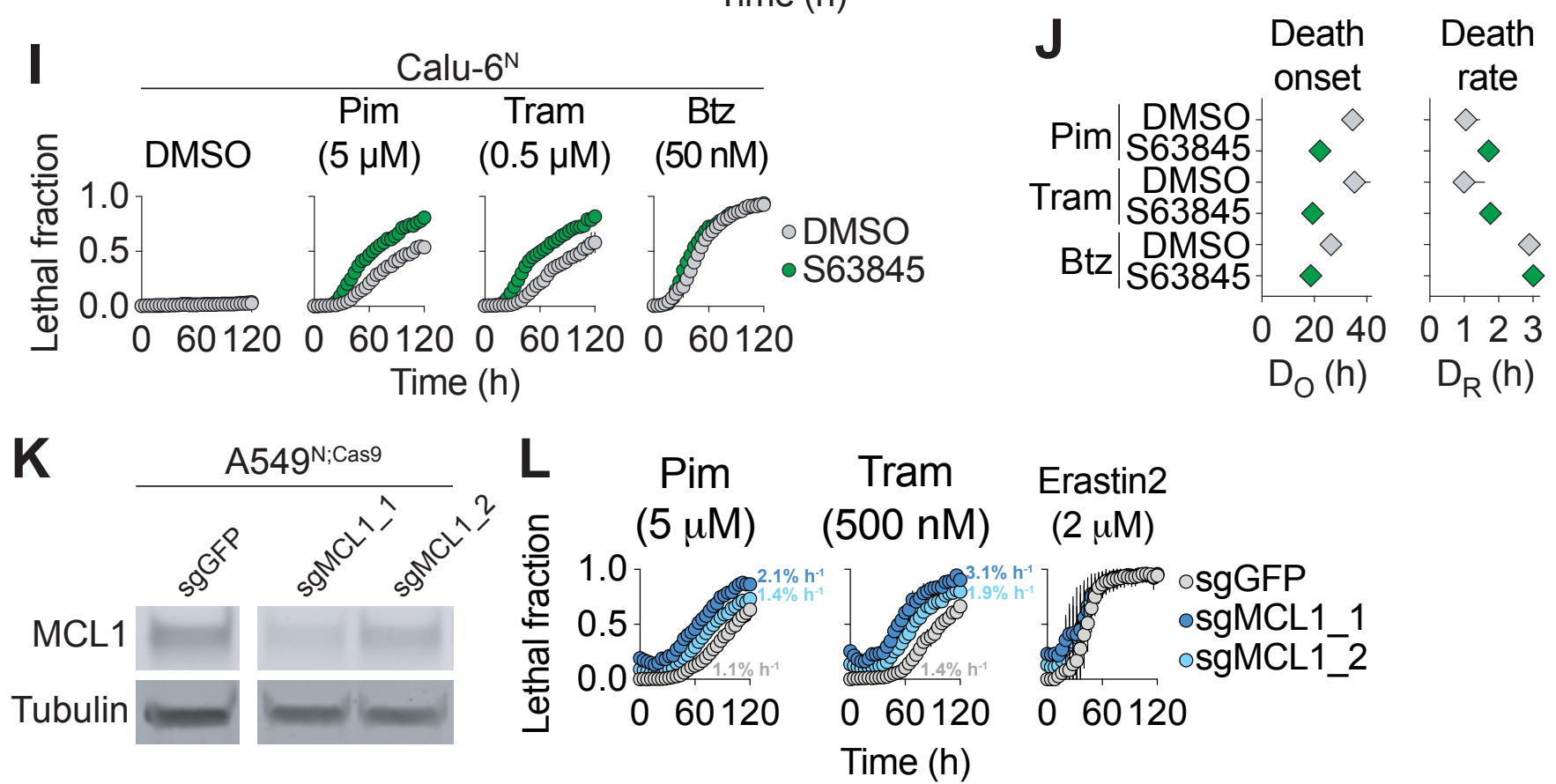

Figure S4, related to Figure 4. (A) Cell death in response to treatment with pimasertib (Pim, $5 \mu \mathrm{M}$ ), trametinib (Tram, $5 \mu \mathrm{M}$ ), bortezomib (Btz, $50 \mathrm{nM})$, camptothecin $(\mathrm{Cpt}, 1 \mu \mathrm{M}) \pm$ cycloheximide $(\mathrm{CHX})$. (B) Cell death \pm Q-VD-OPh $(50 \mu \mathrm{M})$. Pim, Tram and Btz treatments are as in A. (C) Protein expression \pm pimasertib (5 $\mu \mathrm{M}, 48 \mathrm{~h}$ ). (D) Expression of BIM in response to doxycycline (Dox). (E) Cell death over time \pm Pim combined with Dox-inducible expression of wild-type BIM. (F) Cell death kinetic parameters computed from the data in E. (G) Expression of the inactive BIM ${ }^{\mathrm{G} 156 \mathrm{E}}$ mutant + Dox. $(\mathrm{H})$ Cell death over time in response to Dox-inducible expression of mutant BIM ${ }^{\mathrm{G} 156 \mathrm{E}}+$ Pim. $(\mathrm{I})$ Cell death in Calu- $6^{\mathrm{N}}$ cells in response to compound treatment \pm the selective MCL1 inhibitor S63845 (5 $\left.\mu \mathrm{M}\right)$. (J) Cell death kinetic parameters computed from the data in I. (K) Expression of MCL1 in A549 ${ }^{\mathrm{N} ; \mathrm{Cas} 9}$ cells transduced with short guide RNAs against GFP or MCL1. (L) Cell death over time in the cells lines from $\mathrm{K}$, treated as indicated. $\mathrm{D}_{\mathrm{R}}$ values computed from each curve are indicated for MEKis. Data are from at least three independent experiments and represent mean $\pm \mathrm{SD}(\mathrm{A}, \mathrm{B}, \mathrm{E}, \mathrm{H}, \mathrm{I}, \mathrm{L})$ or mean \pm 95\% C.I (F,J). 


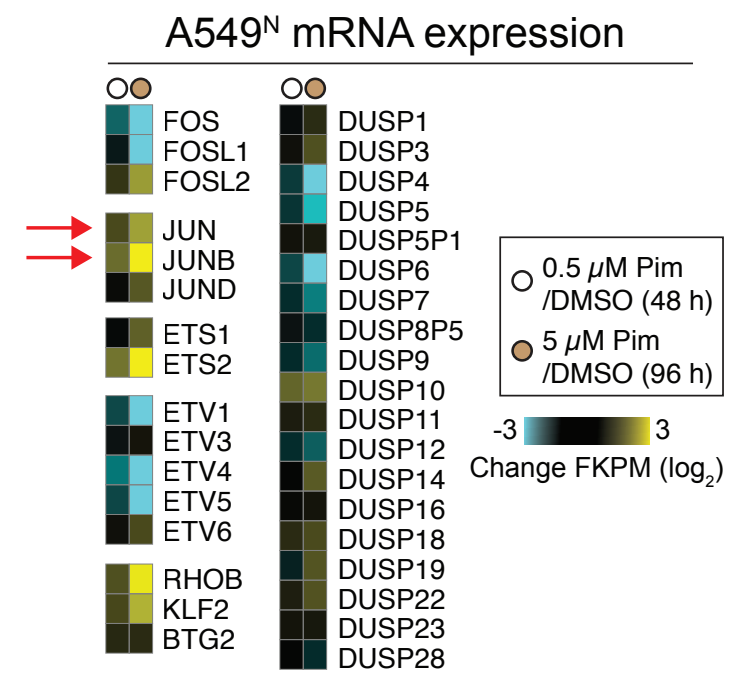

Figure S5, related to Figure 5. Subset of the RNA-seq data presented in Figure 4A, showing relative changes in immediate early genes mRNA. The heatmap represents mean values for two independent biological replicates. 


\section{KEY RESOURCES TABLE}

\begin{tabular}{|c|c|c|}
\hline REAGENT or RESOURCE & SOURCE & IDENTIFIER \\
\hline \multicolumn{3}{|l|}{ Antibodies } \\
\hline Anti-Tubulin alpha (mouse) & Fisher Scientific & $\begin{array}{l}\text { Cat\# } \\
\text { MS581P1 }\end{array}$ \\
\hline Anti-elF4E (mouse) & $\begin{array}{l}\text { Santa Cruz } \\
\text { Biotechnology }\end{array}$ & Cat\# sc-9976 \\
\hline Anti-p44/42 MAPK (Erk1/2) Rabbit mAb & $\begin{array}{l}\text { Cell Signaling } \\
\text { Technology }\end{array}$ & Cat\# 4695 \\
\hline Anti-phospho-p44/42 MAPK (Erk1/2) Rabbit mAb & $\begin{array}{l}\text { Cell Signaling } \\
\text { Technology }\end{array}$ & Cat\# 4370 \\
\hline Anti-DUSP4 (MKP2) Rabbit mAb & $\begin{array}{l}\text { Cell Signaling } \\
\text { Technology }\end{array}$ & Cat\# 5149 \\
\hline Anti-Bim Rabbit mAb & $\begin{array}{l}\text { Cell Signaling } \\
\text { Technology }\end{array}$ & Cat\# 2933 \\
\hline Anti-Bcl-xL Rabbit mAb & $\begin{array}{l}\text { Cell Signaling } \\
\text { Technology }\end{array}$ & Cat\# 2764 \\
\hline Anti-Mcl-1 Rabbit mAb & $\begin{array}{l}\text { Cell Signaling } \\
\text { Technology }\end{array}$ & Cat\# 94296 \\
\hline Anti-phospho-c-Jun (Ser73) Rabbit mAb & $\begin{array}{l}\text { Cell Signaling } \\
\text { Technology }\end{array}$ & Cat\# 3270 \\
\hline Anti-c-Jun Rabbit mAb & $\begin{array}{l}\text { Cell Signaling } \\
\text { Technology }\end{array}$ & Cat\# 9165 \\
\hline $\begin{array}{l}\text { Anti-phospho-S6 Ribosomal Protein (Ser235/236) Rabbit } \\
\text { mAb }\end{array}$ & $\begin{array}{l}\text { Cell Signaling } \\
\text { Technology }\end{array}$ & Cat\# 4858 \\
\hline Anti-S6 Ribosomal Protein Rabbit mAb & $\begin{array}{l}\text { Cell Signaling } \\
\text { Technology }\end{array}$ & Cat\# 2217 \\
\hline Anti-phospho-4E-BP1 (Thr37/46) Rabbit mAb & $\begin{array}{l}\text { Cell Signaling } \\
\text { Technology }\end{array}$ & Cat\# 9459 \\
\hline Anti-4E-BP Rabbit mAb & $\begin{array}{l}\text { Cell Signaling } \\
\text { Technology }\end{array}$ & Cat\# 9644 \\
\hline IRDye 800CW Donkey anti-Rabbit IgG & Licor & $\begin{array}{l}\text { Cat\# 926- } \\
32213\end{array}$ \\
\hline IRDye 800CW Donkey anti-Mouse IgG & Licor & $\begin{array}{l}\text { Cat\# 926- } \\
32212\end{array}$ \\
\hline IRDye 680LT Donkey anti-Rabbit IgG & Licor & $\begin{array}{l}\text { Cat\# 926- } \\
68023\end{array}$ \\
\hline IRDye 680LT Donkey anti-Mouse IgG & Licor & $\begin{array}{l}\text { Cat\# 926- } \\
68022\end{array}$ \\
\hline $\begin{array}{l}\text { Goat polyclonal anti-rabbit highly cross-adsorbed } \\
\text { secondary antibody, Alexa Fluor } 568\end{array}$ & Life Technologies & Cat\# A11036 \\
\hline $\begin{array}{l}\text { Goat polyclonal anti-mouse highly cross-adsorbed } \\
\text { secondary antibody, Alexa Fluor } 488\end{array}$ & Life Technologies & Cat\# A11029 \\
\hline \multicolumn{3}{|l|}{ Bacterial and Virus Strains } \\
\hline $\begin{array}{l}\text { NucLight Red lentivirus reagent (EF1a, Puro) Nuclear- } \\
\text { localized mKate2 (Nuc::mKate2) }\end{array}$ & Essen BioSciences & Cat\# 4265 \\
\hline $\begin{array}{l}\text { NucLight Red lentivirus reagent (EF1a, Bleo) Nuclear- } \\
\text { localized mKate2 (Nuc::mKate2) }\end{array}$ & Essen BioSciences & Cat\# 4627 \\
\hline \multicolumn{3}{|l|}{ Biological Samples } \\
\hline \multicolumn{3}{|l|}{$\mathrm{N} / \mathrm{A}$} \\
\hline \multicolumn{3}{|l|}{ Chemicals, Peptides, and Recombinant Proteins } \\
\hline Puromycin & Life Technologies & $\begin{array}{l}\text { Cat\# A11138- } \\
03\end{array}$ \\
\hline
\end{tabular}




\begin{tabular}{|c|c|c|}
\hline Geneticin & $\begin{array}{l}\text { Thermo Fisher } \\
\text { Scientific }\end{array}$ & $\begin{array}{l}\text { Cat\# 11811- } \\
031\end{array}$ \\
\hline Blasticidin & $\begin{array}{l}\text { Thermo Fisher } \\
\text { Scientific }\end{array}$ & $\begin{array}{l}\text { Cat\# } \\
\text { A1113902 }\end{array}$ \\
\hline Camptothecin & Selleck Chemicals & Cat\# S1288 \\
\hline Vinblastine & Selleck Chemicals & Cat\# S1248 \\
\hline Pimasertib & Selleck Chemicals & Cat\# S1457 \\
\hline Trametinib & Selleck Chemicals & Cat\# S2673 \\
\hline SCH772984 & Selleck Chemicals & Cat\# S7101 \\
\hline ABT-737 & Selleck Chemicals & Cat\# S1002 \\
\hline A-1155463 & Selleck Chemicals & Cat\# S7800 \\
\hline Nutlin-3 & Selleck Chemicals & Cat\# S1061 \\
\hline S63845 & $\begin{array}{l}\text { Cayman Chemical } \\
\text { Company }\end{array}$ & Cat\# 21131 \\
\hline Staurosporine & ApexBio & Cat\# A8192 \\
\hline $\mathrm{N}$-acetylcysteine & Millipore Sigma & Cat\# A8199 \\
\hline Thapsigargin & Millipore Sigma & Cat\# T9033 \\
\hline Tunicamycin & Millipore Sigma & Cat\# T7765 \\
\hline Paclitaxel & Millipore Sigma & Cat\# T7191 \\
\hline JNK Inhibitor VIII & Millipore Sigma & Cat\# 420135 \\
\hline 2-deoxyglucose & Millipore Sigma & Cat\# D8375 \\
\hline Oligomycin & Millipore Sigma & Cat\# 04876 \\
\hline Bortezomib & $\begin{array}{l}\text { Thermo Fisher } \\
\text { Scientific }\end{array}$ & $\begin{array}{l}\text { Cat\# } \\
\text { NC0587961 }\end{array}$ \\
\hline Etoposide & $\begin{array}{l}\text { Thermo Fisher } \\
\text { Scientific }\end{array}$ & $\begin{array}{l}\text { Cat\# } \\
\text { ICN19391825 }\end{array}$ \\
\hline MG-132 & $\begin{array}{l}\text { Thermo Fisher } \\
\text { Scientific }\end{array}$ & Cat\# 17-485 \\
\hline Q-VD-OPh & $\begin{array}{l}\text { Thermo Fisher } \\
\text { Scientific }\end{array}$ & $\begin{array}{l}\text { Cat\# } \\
\text { OPH00101M }\end{array}$ \\
\hline Erastin2 (35MEW28) & Dixon et al., 2014 & N/A \\
\hline Bioactive chemical library (261 compounds) & Selleck Chemicals & Cat\# L2000 \\
\hline Cycloheximide & Sigma-Aldrich & $\begin{array}{l}\text { Cat\# C7698- } \\
1 G\end{array}$ \\
\hline Polybrene & Sigma-Aldrich & $\begin{array}{l}\text { Cat\# H9268- } \\
5 G\end{array}$ \\
\hline Sytox Green & Life Technologies & Cat\# S7020 \\
\hline PolyJet & $\begin{array}{l}\text { SigmaGen } \\
\text { Laboratories }\end{array}$ & Cat\#SL100688 \\
\hline $\mathrm{H}_{2}$ DCFDA & $\begin{array}{l}\text { Thermo Fisher } \\
\text { Scientific }\end{array}$ & Cat\# D-399 \\
\hline DAPI (4',6-Diamidino-2-Phenylindole, Dihydrochloride) & $\begin{array}{l}\text { Thermo Fisher } \\
\text { Scientific }\end{array}$ & Cat\# D1306 \\
\hline FastDigest BstXI & $\begin{array}{l}\text { Thermo Fisher } \\
\text { Scientific }\end{array}$ & Cat\# FD1024 \\
\hline FastDigest Bpu1120I & $\begin{array}{l}\text { Thermo Fisher } \\
\text { Scientific }\end{array}$ & Cat\# FD0094 \\
\hline \multicolumn{3}{|l|}{ Critical Commercial Assays } \\
\hline Gateway LR Clonase II Enzyme Mix & Thermo Fisher & $\begin{array}{l}\text { Cat\# 11791- } \\
020\end{array}$ \\
\hline Gibson Assembly Master Mix & $\begin{array}{l}\text { New England } \\
\text { Biolabs }\end{array}$ & Cat3 E2611S \\
\hline
\end{tabular}




\begin{tabular}{|c|c|c|}
\hline QIAshredder RNA Extraction Column Kit & Qiagen & Cat\# 79654 \\
\hline RNeasy Plus RNA Extraction Kit & Qiagen & Cat\# 74134 \\
\hline TaqMan Reverse Transcriptase Kit & TaqMan & $\begin{array}{l}\text { Cat\# } \\
\text { N8080234 }\end{array}$ \\
\hline QIAprep Spin Miniprep Kit & Qiagen & Cat\# 27106 \\
\hline QIAquick PCR Purification Kit & Qiagen & Cat\# 28106 \\
\hline Q5 Site-Directed Mutagenesis Kit & $\begin{array}{l}\text { New England } \\
\text { Biolabs }\end{array}$ & Cat\# E0554S \\
\hline SYBR Green Master Mix & Life Technologies & Cat\# 4367659 \\
\hline BCA Protein Assay Kit & Thermo Fisher & Cat\# 23225 \\
\hline CellTiter-Glo Luminescent Cell Viability Assay & Promega & Cat\# G7570 \\
\hline PrestoBlue Cell Viability Reagent & Thermo Fisher & Cat\# A13261 \\
\hline \multicolumn{3}{|l|}{ Deposited Data } \\
\hline \multicolumn{3}{|l|}{ N/A } \\
\hline \multicolumn{3}{|l|}{ Experimental Models: Cell Lines } \\
\hline U-2 OS & ATCC & HTB-96 \\
\hline $\mathrm{U}-2 \mathrm{OS}^{\mathrm{N}}$ & Forcina et al., 2017 & N/A \\
\hline T98G & ATCC & CRL-1960 \\
\hline T98G $^{N}$ & Forcina et al., 2017 & $\mathrm{~N} / \mathrm{A}$ \\
\hline A549 & ATCC & CCL-185 \\
\hline A549 & Forcina et al., 2017 & N/A \\
\hline A549 ${ }^{\mathrm{N} ; \mathrm{KTR}}$ & This paper & $\mathrm{N} / \mathrm{A}$ \\
\hline A549 ${ }^{\mathrm{N} ; ~ r t T A-B C L-x L}$ & This paper & $\mathrm{N} / \mathrm{A}$ \\
\hline A549N; rtTA-BIM & This paper & $\mathrm{N} / \mathrm{A}$ \\
\hline A549 & This paper & $\mathrm{N} / \mathrm{A}$ \\
\hline A549 N; CMV-Empty & Cao et al., 2019 & N/A \\
\hline A549 ${ }^{\text {N; CMV-MCL1 }}$ & This paper & $\mathrm{N} / \mathrm{A}$ \\
\hline A549 ${ }^{\mathrm{N} ; \text { Cas9 }}$ & This paper & $\mathrm{N} / \mathrm{A}$ \\
\hline A549 & This paper & N/A \\
\hline A549 N; Cas9; sgMCL1 \#1 & This paper & $\mathrm{N} / \mathrm{A}$ \\
\hline A549 N; Cas9; sgMCL1 \#2 & This paper & N/A \\
\hline A549 ${ }^{\mathrm{N} ;}$ CRISPR Control & This paper & $\mathrm{N} / \mathrm{A}$ \\
\hline A549 N; MCL1-LOF1 & This paper & $\mathrm{N} / \mathrm{A}$ \\
\hline A549 ${ }^{\text {N; MCL1-LOF2 }}$ & This paper & $\mathrm{N} / \mathrm{A}$ \\
\hline Calu-6 & ATCC & HTB-56 \\
\hline Calu- $^{\mathrm{N}}$ & This paper & $\mathrm{N} / \mathrm{A}$ \\
\hline HEK293T & ATCC & CRL-3216 \\
\hline \multicolumn{3}{|l|}{ Experimental Models: Organisms/Strains } \\
\hline \multicolumn{3}{|l|}{$\mathrm{N} / \mathrm{A}$} \\
\hline \multicolumn{3}{|l|}{ Oligonucleotides } \\
\hline \multicolumn{3}{|l|}{ See Table S2. } \\
\hline \multicolumn{3}{|l|}{ Recombinant DNA } \\
\hline pLenti CMVTRE3G BCL2L1 Neo & This paper & $\mathrm{N} / \mathrm{A}$ \\
\hline pLenti CMVTRE3G BCL2L11 Neo & This paper & $\mathrm{N} / \mathrm{A}$ \\
\hline pLenti CMVTRE3G BCL2L11 G156E Neo & This paper & $\mathrm{N} / \mathrm{A}$ \\
\hline pLenti CMV MCL1 Puro & This paper & $\mathrm{N} / \mathrm{A}$ \\
\hline pMCB306 MCL1 sgRNA \#1 & This paper & $\mathrm{N} / \mathrm{A}$ \\
\hline
\end{tabular}


bioRxiv preprint doi: https://doi org/10.1101/2020.02 28 970079. this version posted February 292020 . The copyright holder for this preprint (which was not certified by peer review) is the author/funder, who has granted bioRxiv a license to display the preprint in perpetuity. It is made available under aCC-BY-NC-ND 4.0 International license.

\begin{tabular}{|l|l|l|}
\hline pMCB306 MCL1 sgRNA \#2 & This paper & N/A \\
\hline Other Plasmids & \multicolumn{2}{l|}{} \\
\hline pLentiCMV Puro DEST ERKKTRClover & Addgene & Cat\# 59150 \\
\hline pLentiPGK Puro DEST p38KTRClover & Addgene & Cat\# 59152 \\
\hline pLenti CMV rtTA Blast (w756-1) & Addgene & Cat\# 26429 \\
\hline pLenti CMVTRE3G eGFP Neo (w821-1) & Addgene & Cat\# 27569 \\
\hline pLenti CMV Puro DEST (w118-1) & Addgene & Cat\# 17452 \\
\hline pMCB306 & Addgene & Cat\# 89360 \\
\hline lentiCas9-Blast & Addgene & Cat\# 52962 \\
\hline Software and Algorithms & & \\
\hline Prism & GraphPad Software & N/A \\
\hline Excel & Microsoft Corp. & N/A \\
\hline FlowJo & FlowJo LLC. & N/A \\
\hline CellProfiler & Broad Institute & N/A \\
\hline Data availability & & \\
\hline N/A & & \\
\hline
\end{tabular}




\begin{tabular}{|c|c|c|c|}
\hline CELL LINES ANALYZED & CHANNE & PARAMETER & VALUE/RANGE \\
\hline \multirow[t]{8}{*}{ U-2-OS ${ }^{N}, T 98 G^{N}, A 549^{N}$} & Green & Adaptive Color Processing & $10 \mathrm{GCU}$ \\
\hline & & Area Filter & $20-750 \mu \mathrm{m}^{2}$ \\
\hline & & Eccentricity Filter & $<0.9$ \\
\hline & Red & Adaptive Color Processing & $2 \mathrm{GCU}$ \\
\hline & & Edge Splitting Sensitivity & 9 \\
\hline & & Area Filter & $35-8100 \mu \mathrm{m}^{2}$ \\
\hline & & Eccentricity Filter & $<0.8$ \\
\hline & Overlap & $\mathrm{N} / \mathrm{A}$ & \\
\hline \multirow[t]{7}{*}{ Calu-6 ${ }^{N}$} & Green & Adaptive Color Processing & $10 \mathrm{GCU}$ \\
\hline & & Area Filter & $20-750 \mu \mathrm{m}^{2}$ \\
\hline & & Eccentricity Filter & $<0.9$ \\
\hline & Red & Adaptive Color Processing & $2 \mathrm{GCU}$ \\
\hline & & Edge Splitting Sensitivity & 9 \\
\hline & & Area Filter & $150-8100 \mu \mathrm{m}^{2}$ \\
\hline & Overlap & $\mathrm{N} / \mathrm{A}$ & \\
\hline \multirow[t]{7}{*}{ A549 } & Green & Adaptive Color Processing & $2 \mathrm{GCU}$ \\
\hline & & Edge Splitting Sensitivity & 0 \\
\hline & & Area Filter & $150-600 \mu \mathrm{m}^{2}$ \\
\hline & & Eccentricity Filter & $<0.8$ \\
\hline & & Mean Intensity Filter & $>25$ \\
\hline & Red & Adaptive Color Processing & $2 \mathrm{GCU}$ \\
\hline & Overlap & Area Filter & $>100 \mu m^{2}$ \\
\hline
\end{tabular}

Table S1, Related to STAR Methods. Parameters for IncuCyte analysis. 


\begin{tabular}{|c|c|c|}
\hline OLIGONUCLEOTIDE NAME AND SEQUENCE & SOURCE & IDENTIFIER \\
\hline $\begin{array}{l}\text { CMV MCL1 STOP Site-Directed Mutagenesis Forward } \\
\text { Primer } \\
\text { [5'-TCTAATAAGATAGCCAACTTTCTTGTAC-3'] }\end{array}$ & $\begin{array}{l}\text { This paper, designed using } \\
\text { NEBaseChanger }\end{array}$ & $\mathrm{N} / \mathrm{A}$ \\
\hline $\begin{array}{l}\text { CMV MCL1 STOP Site-Directed Mutagenesis Reverse } \\
\text { Primer } \\
\text { [5'-TATGCCAAACCAGCTCCT-3'] }\end{array}$ & $\begin{array}{l}\text { This paper, designed using } \\
\text { NEBaseChanger }\end{array}$ & $\mathrm{N} / \mathrm{A}$ \\
\hline $\begin{array}{l}\text { CMV MCL1 S64E Site-Directed Mutagenesis Forward } \\
\text { Primer } \\
\text { [5'-CCGGCGCAGAGCCCCCGTCCA-3'] }\end{array}$ & $\begin{array}{l}\text { This paper, designed using } \\
\text { NEBaseChanger }\end{array}$ & $\mathrm{N} / \mathrm{A}$ \\
\hline $\begin{array}{l}\text { CMV MCL1 S64E Site-Directed Mutagenesis Reverse } \\
\text { Primer } \\
\text { [5'-CGCTTCCGCCAATCACCGCGC-3'] }\end{array}$ & $\begin{array}{l}\text { This paper, designed using } \\
\text { NEBaseChanger }\end{array}$ & $\mathrm{N} / \mathrm{A}$ \\
\hline $\begin{array}{l}\text { CMV MCL1 S121A Site-Directed Mutagenesis Forward } \\
\text { Primer } \\
\text { [5'-CGCCATCATGGCGCCCGAAGAGG-3'] }\end{array}$ & $\begin{array}{l}\text { This paper, designed using } \\
\text { NEBaseChanger }\end{array}$ & $\mathrm{N} / \mathrm{A}$ \\
\hline $\begin{array}{l}\text { CMV MCL1 S121A Site-Directed Mutagenesis Reverse } \\
\text { Primer } \\
\text { [5'-TCAGCGGCCGGGGCTTCC-3'] }\end{array}$ & $\begin{array}{l}\text { This paper, designed using } \\
\text { NEBaseChanger }\end{array}$ & $\mathrm{N} / \mathrm{A}$ \\
\hline $\begin{array}{l}\text { CMV MCL1 S159A Site-Directed Mutagenesis Forward } \\
\text { Primer } \\
\text { [5'-TACGGACGGGGCACTACCCTCGA-3'] }\end{array}$ & $\begin{array}{l}\text { This paper, designed using } \\
\text { NEBaseChanger }\end{array}$ & $\mathrm{N} / \mathrm{A}$ \\
\hline $\begin{array}{l}\text { CMV MCL1 S159A Site-Directed Mutagenesis Reverse } \\
\text { Primer } \\
\text { [5'-CTGGTGTTATTACCAGATTCCCCGACC-3'] }\end{array}$ & $\begin{array}{l}\text { This paper, designed using } \\
\text { NEBaseChanger }\end{array}$ & $\mathrm{N} / \mathrm{A}$ \\
\hline $\begin{array}{l}\text { CMV MCL1 T163A Site-Directed Mutagenesis Forward } \\
\text { Primer } \\
\text { [5'-ACTACCCTCGGCGCCGCCGCCAG-3'] }\end{array}$ & $\begin{array}{l}\text { This paper, designed using } \\
\text { NEBaseChanger }\end{array}$ & $\mathrm{N} / \mathrm{A}$ \\
\hline $\begin{array}{l}\text { CMV MCL1 T163A Site-Directed Mutagenesis Reverse } \\
\text { Primer } \\
\text { [5'- } \\
\text { GACCCGTCCGTACTGGTGTTATTACCAGATTCCCC- } \\
\text { 3'] }\end{array}$ & $\begin{array}{l}\text { This paper, designed using } \\
\text { NEBaseChanger }\end{array}$ & $\mathrm{N} / \mathrm{A}$ \\
\hline $\begin{array}{l}\text { Human ACTB qPCR forward primer } \\
\text { [5'-ATCCGCCGCCCGTCCACA-3'] }\end{array}$ & (Tarangelo et al, 2018) & $\mathrm{N} / \mathrm{A}$ \\
\hline $\begin{array}{l}\text { Human ACTB qPCR reverse primer } \\
\text { [5'-ACCATCACGCCCTGGTGCCT-3'] }\end{array}$ & (Tarangelo et al, 2018) & $\mathrm{N} / \mathrm{A}$ \\
\hline $\begin{array}{l}\text { Human JUN qPCR forward primer } \\
\text { [5'-GAGAGGAAGCGCATGAGGAA-3'] }\end{array}$ & (Kolomeichuk et al, 2008) & $\mathrm{N} / \mathrm{A}$ \\
\hline $\begin{array}{l}\text { Human JUN qPCR reverse primer } \\
\text { [5'-CCAGCCGGGCGATTC-3'] }\end{array}$ & (Kolomeichuk et al, 2008) & $\mathrm{N} / \mathrm{A}$ \\
\hline $\begin{array}{l}\text { Human JUNB qPCR forward primer } \\
\text { [5'-ACGACTCATACACAGCTACGG-3'] }\end{array}$ & $\begin{array}{l}\text { This paper, MGH Primer Bank } \\
\text { (Spandidos et al, 2010) }\end{array}$ & $\mathrm{N} / \mathrm{A}$ \\
\hline $\begin{array}{l}\text { Human JUNB qPCR reverse primer } \\
\text { [5'-GCTCGGTTTCAGGAGTTTGTAGT-3'] }\end{array}$ & $\begin{array}{l}\text { This paper, MGH Primer Bank } \\
\text { (Spandidos et al, 2010) }\end{array}$ & $\mathrm{N} / \mathrm{A}$ \\
\hline $\begin{array}{l}\text { Human ETS1 qPCR forward primer } \\
\text { [5'-GATAGTTGTGATCGCCTCACC-3'] }\end{array}$ & $\begin{array}{l}\text { This paper, MGH Primer Bank } \\
\text { (Spandidos et al, 2010) }\end{array}$ & $\mathrm{N} / \mathrm{A}$ \\
\hline $\begin{array}{l}\text { Human ETS1 qPCR reverse primer } \\
\text { [5'-GTCCTCTGAGTCGAAGCTGTC-3'] }\end{array}$ & $\begin{array}{l}\text { This paper, MGH Primer Bank } \\
\text { (Spandidos et al, 2010) }\end{array}$ & $\mathrm{N} / \mathrm{A}$ \\
\hline $\begin{array}{l}\text { Human DUSP1 qPCR forward primer } \\
\text { [5'-AGTACCCCACTCTACGATCAGG-3'] }\end{array}$ & $\begin{array}{l}\text { This paper, MGH Primer Bank } \\
\text { (Spandidos et al, 2010) }\end{array}$ & $\mathrm{N} / \mathrm{A}$ \\
\hline $\begin{array}{l}\text { Human DUSP1 qPCR reverse primer } \\
\text { [5'-GAAGCGTGATACGCACTGC-3'] }\end{array}$ & $\begin{array}{l}\text { This paper, MGH Primer Bank } \\
\text { (Spandidos et al, 2010) }\end{array}$ & $\mathrm{N} / \mathrm{A}$ \\
\hline
\end{tabular}




\begin{tabular}{|l|l|l|}
\hline $\begin{array}{l}\text { Human DUSP4 qPCR forward primer } \\
\text { [5'-GGCGGCTATGAGAGGTTTCC-3'] }\end{array}$ & $\begin{array}{l}\text { This paper, MGH Primer Bank } \\
\text { (Spandidos et al, 2010) }\end{array}$ & N/A \\
\hline $\begin{array}{l}\text { Human DUSP4 qPCR reverse primer } \\
\text { [5'-TGGTCGTGTAGTGGGGTCC-3'] }\end{array}$ & $\begin{array}{l}\text { This paper, MGH Primer Bank } \\
\text { (Spandidos et al, 2010) }\end{array}$ & N/A \\
\hline $\begin{array}{l}\text { sgMCL1 with adaptors for pSpCas9-2A-EGFP top strand } \\
\text { [5'-caccgGTTTGGCCTCAAAAGAAACG-3'] }\end{array}$ & $\begin{array}{l}\text { This paper, designed using } \\
\text { Synthego Guide Design Tool }\end{array}$ & N/A \\
\hline $\begin{array}{l}\text { sgMCL1 with adaptors for pSpCas9-2A-EGFP bottom } \\
\text { strand } \\
\text { [5'- aaacCGTTTCTTTTGAGGCCAAACc-3'] }\end{array}$ & $\begin{array}{l}\text { This paper, designed using } \\
\text { Synthego Guide Design Tool }\end{array}$ & N/A \\
\hline $\begin{array}{l}\text { sgMCL1 \#1 with adaptors for pMCB306 top strand } \\
\text { [5'-ttggGTTTGGCCTCAAAAGAAACGgtttaagagc-3'] }\end{array}$ & $\begin{array}{l}\text { This paper, designed using } \\
\text { Synthego Guide Design Tool }\end{array}$ & N/A \\
\hline $\begin{array}{l}\text { sgMCL1 \#1 with adaptors for pMCB306 bottom strand } \\
\text { [5'- } \\
\text { ttagctcttaaacCGTTTCTTTTGAGGCCAAACccaacaag-3'] }\end{array}$ & $\begin{array}{l}\text { This paper, designed using } \\
\text { Synthego Guide Design Tool }\end{array}$ & N/A \\
\hline $\begin{array}{l}\text { sgMCL1 \#2 with adaptors for pMCB306 top strand } \\
\text { [5'-ttggATCGGACTCAACCTCTACTGgtttaagagc-3'] }\end{array}$ & $\begin{array}{l}\text { This paper, designed using } \\
\text { Synthego Guide Design Tool }\end{array}$ & N/A \\
\hline $\begin{array}{l}\text { sgMCL1 \#2 with adaptors for pMCB306 bottom strand } \\
\text { [5'- ttagctcttaaac }\end{array}$ & $\begin{array}{l}\text { This paper, designed using } \\
\text { CAGTAGAGego Guide Design Tool }\end{array}$ & N/A \\
\hline
\end{tabular}

Table S2, Related to STAR Methods. Oligonucleotides used in this study. 